UNIVERSIDADE DE SÃO PAULO

FACULDADE DE ODONTOLOGIA DE RIBEIRÃO PRETO

CARLA GABALDO PESSOA DOS SANTOS

AVALIAÇÃO DA PASSAGEM DE MICRO-ORGANISMOS POR MEIO

DA INTERFACE ENTRE IMPLANTES E CONECTORES PROTÉTICOS COM PARAFUSOS CONVENCIONAIS PLANOS E EXPERIMENTAIS CÔNICOS PELA TÉCNICA DNA-CHECKERBOARD

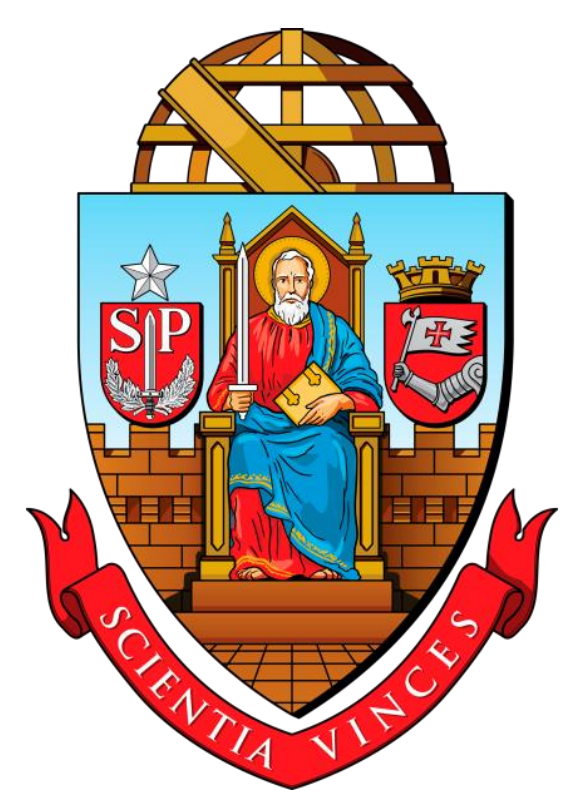

Ribeirão Preto -2016 - 

CARLA GABALDO PESSOA DOS SANTOS

\title{
AVALIAÇÃO DA PASSAGEM DE MICRO-ORGANISMOS POR MEIO \\ DA INTERFACE ENTRE IMPLANTES E CONECTORES PROTÉTICOS COM PARAFUSOS CONVENCIONAIS PLANOS E EXPERIMENTAIS CÔNICOS PELA TÉCNICA DNA-CHECKERBOARD
}

\author{
Dissertação apresentada à Faculdade de \\ Odontologia de Ribeirão Preto, da \\ Universidade de São Paulo, para obtenção \\ do título de Mestre em Odontologia. \\ Área de concentração: Reabilitação Oral \\ Orientador: Prof. Dr. Vinícius Pedrazzi
}

Ribeirão Preto 
AUTORIZO A REPRODUÇÃO E DIVULGAÇÃO DO TEOR TOTAL OU PARCIAL DESTE TRABALHO POR QUALQUER MEIO CONVENCIONAL OU ELETRÔNICO, PARA FINS DE ESTUDO E PESQUISA, DESDE QUE CITADA A FONTE.

Ficha catalográfica elaborada pela Biblioteca Central do Campus - USP Ribeirão Preto

Pessoa, Carla Gabaldo

Avaliação da passagem de micro-organismos por meio da interface entre implantes e conectores protéticos com parafusos convencionais planos e experimentais cônicos, pela técnica DNA-Checkerboard. Ribeirão Preto, 2016.

111 p.: il.; $30 \mathrm{~cm}+1 \mathrm{CD}-\mathrm{ROM}$

Dissertação de Mestrado, apresentada à Faculdade de Odontologia de Ribeirão Preto/USP. Área de Concentração: Reabilitação Oral.

Orientador: Pedrazzi, Vinícius.

1. Microbiologia 2. DNA-Checkerboard. 3. Infiltração bacteriana. 4. Implantes dentários. 


\section{FOLHA DE APROVAÇÃO}

Pessoa, CG. Avaliação da passagem de micro-organismos por meio da interface entre implantes e conectores protéticos com parafusos convencionais planos e experimentais cônicos, pela técnica DNACheckerboard

Dissertação apresentada à Faculdade de Odontologia de Ribeirão Preto, da Universidade de São Paulo, para obtenção do título de Mestre em Odontologia.

Área de Concentração: Reabilitação Oral

Aprovada em:

Banca Examinadora:

1) Prof. Dr.:

Instituição:

Julgamento: Assinatura:

2) Prof. Dr.:

Instituição:

Julgamento: Assinatura:

3) Prof. Dr.:

Instituição:

Julgamento: Assinatura:

4) Prof. Dr.:

Instituição:

Presidente da Comissão Julgadora 




\section{Dedicatória}

À minha amada filha Laura, que me fez acreditar que cada sonho poderia ser possivel. Ao meu marido Farley, que com toda compreensão me apoiou todos esses anos. $\dot{A}$ minha mãe Carmen, que sempre me incentivou e acreditou em cada gesto de esforço, sendo meu alicerce em cada passo dado de minha vida. Dedico esse trabalho como uma forma de agradecimento.

\section{Minha eterna e sincera gratidão. Amo muito todos vocês!}

Aos meus maiores exemplos, meus irmãos Caroline e Gustavo, ao meu tio Carlos, e à minha querida avó $\mathbb{E} l z a$, por fazer possível o caminho escolhido por mim e por sempre estarem ao meu lado quando precisei. 

Agradecimentos Especiais 



\section{Agradecimentos especiais}

Meus sinceros agradecimentos

Ao meu querido orientador, Prof. Dr. Vinícius Pedrazzi, agradeço pela oportunidade, pela paciência e compreensão. Rezo a Deus para que a sua presença continue distribuindo fé e esperança no caminho daqueles que um dia se apoiaram em teu exemplo. Obrigada por ter sido muito além de um professor. Àquele que foi meu amigo e pai. Àquele que me fez lembrar o quão linda e preciosa a Odontologia pode ser.

Que Deus te ilumine.

Ao Prof. Dr. Cássio do Nascimento, que com toda sua paciência e prestatividade, soube nos conduzir e fazer possível cada etapa de nossa Pesquisa nesses dois anos de convívio, sendo imprescindível para a concretização desta dissertação.

Aos meus sogros Antônio e Maria Rita pelo suporte em tantos momentos de necessidade.

Muito Agradecida 

Agradecimentos 



\section{Agradecimentos}

A Deus, por ter me dado forças para superar mais um desafio ao longo dessa caminhada.

À Faculdade de Odontologia de Ribeirão Preto da Universidade de São Paulo, que me deu a oportunidade de reafizar esse sonho. Esta que considero minha segunda casa e da qual tenho um imenso orgulho, por todo conhecimento adquirido durante todos estes anos, onde obtive minha formação como Cirurgiã-Dentista e pela oportunidade da realização do curso de Mestrado. Agradeço carinhosamente à Diretora, Profa. Dra. Léa Assed Bezerra da Silva ao Vice-Diretor, Prof. Dr. Prof. Dr. Arthur Belem Novaes Júnior por serem os nossos pilares durante essa trajetória.

Aos docentes do Departamento de Materiais Dentários e Prótese da Faculdade de Odontologia de Ribeirão Preto, nas pessoas da chefe de Departamento, Profa. Dra. Valéria Oliveira Pagnano de Souza, por ter despertado em mim o sonho da pós-graduação e por ser um exemplo admirável de pessoa e pelo afável convívio e pela contribuição indispensável para minha formação como Mestre.

À Coordenadora do Programa de Pós-Graduação na área de Reabilitação Oral, Profa. Dra. Rossana Pereira de Almeida Antunes, pelo excelente trabalho realizado no curso, pelo apoio e incentivos constantes.

Às funcionárias do Departamento de Materiais Dentários e Prótese, Regiane de Cássia Tirado Damasceno, Fernanda Talita de Freitas, e Denise Martins Fontes Gonçalves, pela paciência e prestatividade em me ajudar sempre que precisei.

A todos os funcionários do Departamento de Materiais Dentários e Prótese, e da FORP-USP, pela alegre convivência e pela boa vontade com que me ajudaram sempre que foi preciso. 
À Mary Possani Carmessano e à Rosana Margareth Mendonça Prates, secretárias da pós-graduação, eficientes e responsáveis durante a jornada de trabalho e pela disponibilidade em me atender sempre que necessário.

Ao Professor Dr. Ricardo Faria Ribeiro, pelos conselhos e contribuição durante esses dois anos de aprendizado.

Aos amigos Ana Carolina Roque, Carolina Soronha, João Henrique Fortes, Mônica Bastos, Paulo Linares, Priscila Raile, Raphael Jurca, e Raony Molin pelo companheirismo, conselhos, generosidade, e, sobretudo, por estarem ao meu lado em cada necessidade.

Um especial agradecimento ao Cirurgião-Dentista Murilo Suscena Pitta, e aluna de iniciação científica Isabela Mirales Pires, por toda ajuda para a realização desta pesquisa.

Ao meu amigo e conselheiro Thalisson Saymo, por prestar toda a assistência incondicional durante essa jornada.

À Capes (Coordenação de Aperfeiçoamento de Pessoal de Nivivel Superior, do Ministério da Educação-MEEC), pela 6olsa de estudo fornecida, que em muito me auxiliou neste momento tão importante de minha vida.

A todos que, direta ou indiretamente, colaboraram com a realização deste trabalho.

Muito Agradecida. 
"Viva como se fosse morrer amanhã.

Aprenda como se fosse viver para sempre..." 

Resumo 

Pessoa, Carla Gabaldo. Avaliação Da Passagem De Micro-Organismos Por Meio Da Interface Entre Implantes E Conectores Protéticos Com Parafusos Convencionais Planos E Experimentais Cônicos, Pela Técnica DNA-Checkerboard. 2016. $111 \mathrm{f}$. Dissertação (Mestrado)-Faculdade de Odontologia de Ribeirão Preto, Universidade de São Paulo, Ribeirão Preto.

\section{RESUMO}

Apesar da confiabilidade e da sobrevivência relacionadas aos tratamentos com implantes, falhas das reabilitações orais implanto-suportadas ainda são persistentes. Estas falhas podem causar tanto danos mecânicos -como o afrouxamento do parafuso de retenção devido à instabilidade das conexões- quanto danos biológicos -como as reações inflamatórias nos tecidos peri-implantares devido à ocorrência de infiltração bacteriana através da interface implante/pilar e a consequente colonização do interior dos implantes e seus componentes. Os mecanismos responsáveis por estas falhas mecânicas/biológicas dos sistemas de implantes não estão totalmente elucidados, e modificações nos modelos das conexões protéticas e dos parafusos de retenção vêm sendo desenvolvidas com o intuito de aumentar a estabilidade das conexões e minimizar estas intercorrências. Entretanto, a literatura relativa à configuração ideal destas modificações e seus fatores determinantes envolvidos ainda é inconclusiva. Assim, os objetivos do presente do estudo foram avaliar microbiologicamente por meio da técnica de hibridização DNA-Checkerboard, a ocorrência de infiltração bacteriana do meio externo para o interior dos implantes através das diferentes interfaces implante/pilar em dois diferentes sistemas de conexão de implantes, hexágono externo (HE) e triângulo interno (TI), com parafusos de retenção de pilares planos convencionais e parafusos experimentais cônicos. Quarenta e oito implantes dos dois tipos de conexão foram analisados, sendo estes HE $(n=24)$ ou $\mathrm{TI}(n=24)$. Os pilares foram fixados a implantes com parafusos convencionais ou parafusos cônicos experimentais. Após a incubação em saliva, a hibridização DNA Checkerboard foi utilizada para identificar e quantificar até 38 espécies bacterianas na área interna dos implantes. Para análise estatística utilizou-se o teste de Kruskal-Wallis seguido de pós-testes de Bonferroni para comparações múltiplas. Vinte e quatro das trinta e oito espécies estudadas, incluindo patógenos putativos periodontais, foram encontradas colonizando as superfícies internas dos implantes HE $\mathrm{E}$ TI. Peptostreptococcus anaerobios ( $P=0,003)$, Prevotella melaninogenica $(P<0,0001)$ e Candida dubliniensis ( $\mathrm{P}<0,0001$ ) apresentaram diferenças significativas entre os diferentes grupos. As médias de contagem microbiana total ( $\times 104, \pm$ DP) para cada grupo foram registradas como: $G 1(0,27 \pm 2,04), G 2(0 \pm 0), G 3(1,81 \pm 7,50)$ e $G 4(0,35$ \pm 1,81). As diferentes geometrias das conexões de implantes e parafusos apresentaram distintos níveis de penetração microbiana através da interface implante-pilar. Os implantes ligados com parafusos de pilar de cabeça cônica experimental apresentaram contagens menores de micro-organismos quando comparados com os parafusos convencionais.

Palavras-chave: Microbiologia; DNA-Checkerboard; Infiltração bacteriana; Implantes dentários. 

Abstract 

Pessoa, Carla Gabaldo. Evaluation of microorganisms leakage through the interface between implants and prosthetic connectors with conventional plane and experimental conical screws by DNA-Checkerboard technique. $2016.111 \mathrm{f}$. [Dissertation]. Ribeirão Preto: University of São Paulo, School of Dentistry of Ribeirão Preto.

\begin{abstract}
Despite the reliability and high success rates related to treatment with implants, failures of implant-supported oral rehabilitation are still persistent. These failures can cause both mechanical damage, such as loosening the retaining screw connections due to instability, as biological damage, such as inflammatory reactions in periimplants tissues due to the occurrence of bacterial leakage along the implant/abutment interface and the subsequent colonization of the subsequent colonization of the internal/inner parts of the implants and components. The mechanisms responsible for these mechanical/biological failures of implant systems are not fully elucidated, and changes to the models of prosthetic connections and retaining screws have been developed in order to increase the stability of connections and minimize these problems. However, the literature related to these changes and its impact on the implant-components stability is still inconclusive. The objective of this study was to evaluate microbiologically by the DNA-Checkerboard hybridization, the occurrence of bacterial leakage from the external environment to the interior of the implant through these different implant/abutment interface. For the study will be evaluated two different implant connections, one external hexagonal (EH) and other internal triangle (IT), with either conventional and experimental tapered screws abutment. Forty-eight two-part implants with external hexagon ( $\mathrm{EH} ; \mathrm{n}=24$ ) or tri-channel internal ( $\mathrm{Tl} ; \mathrm{n}=24$ ) connections were investigated. Abutments were attached to implants with conventional flat-head or experimental conical-head screws. After saliva incubation, Checkerboard DNA-DNA hybridization was used to identify and quantify up to 38 bacterial colonizing the internal parts of the implants. Kruskal-Wallis test followed by Bonferroni's post-tests for multiple comparisons was used for statistical analysis. Twenty-four of thirty-eight species, including putative periodontal pathogens, were found colonizing the inner surfaces of both $\mathrm{EH}$ and $\mathrm{Tl}$ implants. Peptostreptococcus anaerobios $(P=0.003)$, Prevotella melaninogenica $(P<0.0001)$, and Candida dubliniensis $(P<0.0001)$ presented significant differences between different groups. Means of total microbial count $(\times 104, \pm S D)$ for each group were recorded as follows: $G 1$ (0.27 \pm 2.04$), G 2(0 \pm 0), G 3$ $(1.81 \pm 7.50)$, and $G 4(0.35 \pm 1.81)$. Differences in the geometry of implant connections and abutment screws have impacted the microbial leakage through the implant-abutment interface. Implants attached with experimental conical-head abutment screws showed lower counts of microorganisms when compared with conventional flat-head screws.
\end{abstract}

Keywords: Microbiology; DNA-Checkerboard; Bacterial leakage; Dental implants. 



\section{Lista de Abreviaturas}





\section{LISTA DE SIGLAS E ABREVIATURAS}

HE - Hexagono Externo

TI - Triângulo Interno

CM - Cone Morse

pH - Potencial Hidrogeniônico

FORP-USP - Faculdade de Odontologia de Ribeirão Preto da USP

USP - Universidade de São Paulo

LabDom - Laboratório de Diagnóstico Odontológico Molecular

CAAE - Certificado de Apresentação para Apreciação Ética

TE - Tampão Tris-Acetato-EDTA

EDTA - Ácido etilenodiamino tetra-acético

$\mathrm{NaOH}$ - Hidróxido de Sódio

Nacl - Cloreto de Sódio

PVC - Policloreto de Vinila

cm - Centímetro

ng - Nanograma

$\boldsymbol{\mu L}$ - Microlitro

$\mathrm{mL}-$ Mililitro

M - Mol

rpm - Rotação por minuto

p - Nível de significância

DP - Desvio Padrão

${ }^{\circ} \mathrm{C}$ - Grau Celsius

Tris-HCl-Cloridrato de Trizma

(EEG) - Equações Estimativas Generalizadas

ATCC - American Type Culture Collection 

Lista de Figuras 



\section{LISTA DE FIGURAS}

Figura1. Pilares, implantes e chave manual (DÉRIG ${ }^{\circledR}$, São Paulo, Brasil)......... 72

Figura 2. Torque final dado com um torquímetro (DÉRIG ${ }^{\circledR}$, São Paulo, Brasil)

Figura 3. Conjunto Implante/Pilares Parcialmente imerso em solução de saliva humana em microtubos.

Figura 4. Remoção do conteúdo sendo colhido com o auxílio de escovas do tipo microbrush............................................................................ 73

Figura 5. Amostra transferida para o microtubo para processamento.

Figura 6. Tubos agitados por 4 minutos para a desagregação do conteúdo colhido pela escova.

Figura 7. Aplicação das amostras sobre a membrana nylon Hybond $\mathrm{N}+\ldots . . .79$

Figura 8. Membrana posicionada no Miniblotter 45 com as linhas contendo o DNA fixado das amostras perpendiculares às canaletas do aparelho

Figura 9. Membrana posicionada no interior do cassete, e sobre ela posicionado o filme radiográfico Hyperfilm (GE Healthcare, UK)....

Figura 10. Membranas após exposição radiográfica, ilustrando o Grupol (A), Grupo 2 (B), Grupo 3 (C) e grupo 4 (D) 

Lista de Tabelas e Gráficos 



\section{LISTA DE TABELAS E GRÁFICOS}

Tabela 1. Dimensões dos implantes, pilares e parafusos

Tabela 2. Espécies microbianas (e seus respectivos números ATCC) utilizadas para a preparação das sondas de DNA alvoespecíficas.

Tabela 3. Média, mediana, menor e maior quartil das contagens microbianas (x104 \pm DP) e seus respectivos valores de $p$, avaliados pela técnica de hibridização DNA Checkerboard nos grupos testados.

\section{LISTA DE GRÁFICOS}

Gráfico 1. Scatter da contagem de genoma microbiano total, com mediana e intervalo interquartil para grupos testados 

Sumário 



\section{SUMÁRIO}

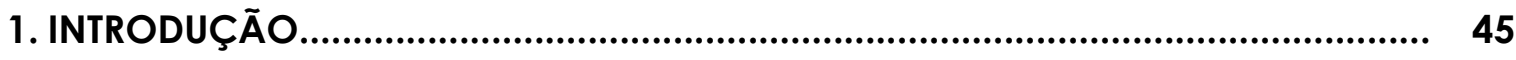

2. REVISTA DE LITERATURA .......................................................................... 51

2.1 Implantes dentários................................................................................ 53

2.2 Sobrevivência e Causas de Falhas nos Implantes Dentários....................... 55

2.3 DNA-Checkerboard como técnica de avaliação microbiológica............ 58

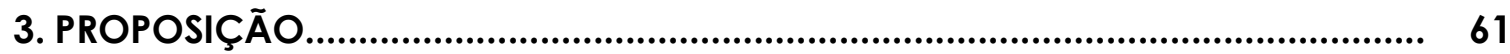

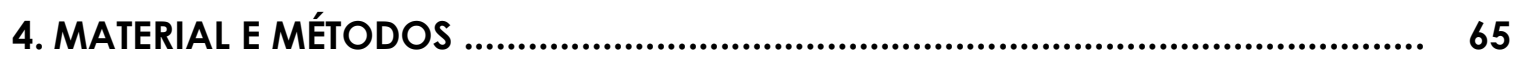

4.1 Análises Microbiológicas.......................................................................... 67

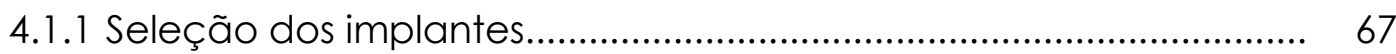

4.1.2 Obtenção da Saliva......................................................................... 69

4.1.3 Teste de Contaminação..................................................................... 71

4.1.4 Colheita das amostras...................................................................... 72

4.1.5 Identificação e quantificação dos micro-organismos pelo método de hibridização DNA Checkerboard.................................. 74

4.2 Extração do DNA para a confecção das sondas dos micro-

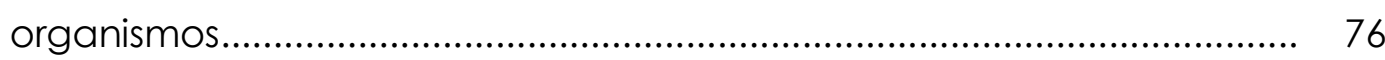

4.3 Purificação e quantificação do DNA......................................................... 76

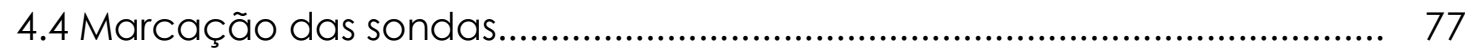

4.5 Teste de sensibilidade e especificidade das sondas dos micro-

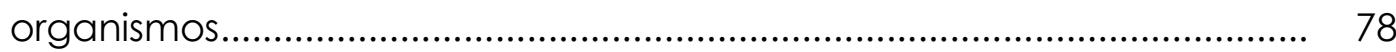

4.6 Processamento das amostras................................................................. 78

4.7 Aplicação das sondas e reação de hibridização........................................ 79

4.8 Detecção dos sinais de hibridização.......................................................... 80

4.9 Interpretação dos sinais.......................................................................... 82

5. RESULTADOS

5.1 Forma de análise dos resultados............................................................. 85

6. DISCUSSÃO

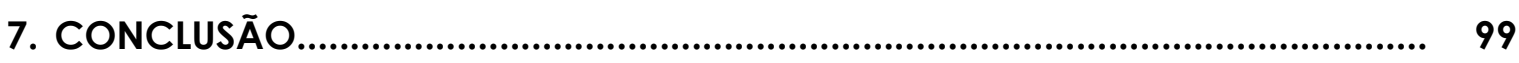

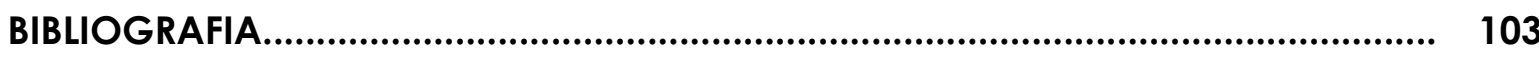

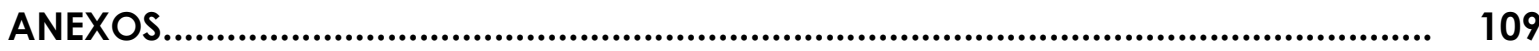



1. Introdução 



\section{INTRODUÇÃO}

Desde os estudos preliminares sobre a osseointegração, os implantes dentários têm sido amplamente utilizados para a reabilitação de pacientes parcial ou totalmente edêntulos ao longo das últimas décadas (Brånemark et al., 1967 e 1977), representando um dos mais importantes avanços terapêuticos da odontologia moderna (Pita et al., 2008).

Apesar da sobrevivência dos implantes relatada por um grande número de estudos clínicos, complicações nos implantes e conexões protéticas ainda são persistentes (Sakaguchi e Borgersen, 1995; Merz et al.,2000; Schwarz, 2000; Teixeira et al., 2011; Pita MS, 2013).

As falhas, em especial as tardias que ocorrem após o período da osseointegração, têm sido frequentemente relatadas durante a fase do tratamento protético e são principalmente relacionadas às complicações mecânicas, devido à sobrecarga, fadiga e instabilidade dos componentes. Como consequência, o afrouxamento dos parafusos de fixação do pilar intermediário ou de retenção da coroa protética são as intercorrências mais prevalentes (Taylor et al., 2000; Akour et al., 2005; Guda et al., 2008; Teixeira et al., 2011, do Nascimento et al, 2012).

Outro fator fundamental para tal questão é a adaptação entre estes componentes. A desadaptação ou gap pode gerar também danos biológicos, como as peri-implantites e mucosites, relacionadas à dificuldade de higienização e retenção de bactérias nos espaços entre os mesmos (Quirynen et al., 1994, do Nascimento et al., 2012). 
A passagem de algumas espécies de bactérias através dos parafusos de fixação dos conectores e próteses, do interior de implantes para o meio externo e em sentido contrário, foi observada em alguns experimentos in vitro (Jansen et al., 1997; Guindy et al., 1998; Steinebrunner et al., 2005; do Nascimento et al., 2008; Teixeira et al., 2011, do Nascimento et al., 2012).

Segundo Khraisat et al. (2006) a presença e o tamanho das fendas entre os implantes e conectores podem variar de acordo com o tipo de conexão dos implantes e com as características dos conectores. Logo, os aspectos biomecânicos das próteses implanto-suportadas são consensualmente significativos, especialmente durante o planejamento dos tratamentos reabilitadores e do desenvolvimento dos modelos de componentes e conexões protéticas (Assunção et al., 2009, Teixeira et al., 2011).

Seguindo-se este princípio, diversas interfaces de conexão implante/pilar foram desenvolvidas para suportar restaurações protéticas. Estes modelos de interface podem ser classificados como conexões externas ou internas, e incorporar características para resistência rotacional, indexação e estabilização lateral. Alguns destes modelos podem ser descritos como hexagonal (externo ou interno), octogonal, cônico, cônico com hexágono, cônico com octógono, cilíndrico com hexágono, com estrias, câmaras, câmaras em tubo (triângulo interno ou tri-channel), e pino/fenda (Quek et al., 2008).

Além de mudanças nos modelos dos implantes, pesquisadores e 
fabricantes buscam o desenvolvimento de novos tipos de parafusos de retenção e fixação com diferentes geometrias e composições de superfície, com o intuito de que estes parafusos aumentem a estabilidade das conexões parafusadas (Martin et al., 2001). Corroborando com este conceito, recentemente foram idealizados e desenvolvidos experimentalmente parafusos com conicidade de 25 graus entre a cabeça e a haste correspondente à área dos seus respectivos encaixes aos pilares (Coppedê, 2011).

Apesar dos resultados promissores apresentados por este estudo, ainda há a necessidade de projetos mais específicos com análises microbiológicas para a avaliação do comportamento biomecânico/biológico e uma avaliação conclusiva da configuração ideal destes parafusos. 

2. Revista da Literatura 



\section{REVISTA DA LITERATURA}

\subsection{Implantes dentários}

BRÅNEMARK et al. (1969) definiram o conceito de osseointegração como a possibilidade de ancoragem direta da estrutura do implante no osso, sem que houvesse a presença de tecido conjuntivo nessa interface.

Segundo Skalak (1983), qualquer falha na adaptação do conjunto prótese-implante-osso resultará em estresse interno do sistema, influenciando noo sucesso da osseointegração. Alguns requisitos devem ser respeitados para se alcançar a osseointegração, como por exemplo a biocompatibilidade do material, formato do implante, técnicas cirúrgicas que possibilitem uma preparação atraumática osséa e instalação do implante, assim como respeitar o período de cicatrização óssea sem aplicação de carga (BRÅNEMARK, 1985).

A biointegração, que é definida como a união química do implante com o osso (MEFFERT et al.,1992), foi desenvolvido com o uso de materiais, como a hidroxiapatita ou fosfato tricálcio, que não apresentavam espaços entre tecido calcificado e o material de implante, em nível de microscopia eletrônica de varredura.

Gustav Dahl, em 1943, desenvolveu os implantes subperiosteais (Magini, 1999). Em 1967, Scialon criou os implantes agulhados e, Linkov, os laminados (Resende, 1994). Segundo Hobo et al. (1997), a implantodontia moderna começou na década de 40, com o surgimento de um implante 
parafusado desenvolvido por Formiggini. Após anos de estudo, vários tipos de implantes foram sendo desenvolvidos.

De acordo com Teixeira et al. (2011), o sucesso a longo prazo dos implantes depende de vários fatores. O desenho na remodelação óssea em volta do implante formado imediatamente após sua inserção óssea e com o passar do tempo favorece ou não a manutenção deste na cavidade oral. A excessiva perda óssea não é aceitável, pois leva a um aumento de bolsas favorecendo o acúmulo de placa bacteriana subgengival, ocasionando, assim, o risco de infecção nessa porção cervical do implante, comprometendo a implantação.

Quirynen et al. (2005) avaliaram clínica e microbiologicamente o comportamento de implantes após 10 anos de sua colocação em 37 pacientes desdentados e tratados com próteses totais superiores convencionais, e próteses inferiores retidas a implantes (Branemark System, Nobel Biocare) por pelo menos 10 anos. O estudo contou com dois grupos de pacientes. O grupo 1 consistiu de 25 pacientes tratados com overdenture. O grupo 2 consistiu de 12 pacientes reabilitados com próteses fixas. Amostras bacterianas subgengivais foram removidas de dois implantes de cada paciente para posterior análise microbiológica. As amostras foram analisadas utilizando a técnica de hibridização de DNA. Após 10 anos de carga, a microbiota subgengival dos implantes de todos os grupos foram comparáveis entre si, apresentando baixa prevalência de espécies bacterianas, mas alta detecção para os microorganismos Aggregatibacter actinomycetemcomitans, Porphyromonas gingivalis e Tannerella forythensis, 
pertencentes ao complexo vermelho. A média do índice de placa, sangramento à sondagem e altura do nível ósseo marginal não foi significantemente diferente, nem entre o grupo que utilizava overdenture e nem entre o que utilizava prótese fixa, uma vez passado o período de acompanhamento clínico. Desta forma, evidenciaram-se a possibilidade de viabilidade clínica da manutenção destes implantes em ambos os tipos de tratamento reabilitador na cavidade oral.

\subsection{Sobrevivência e Causas de Falhas nos Implantes Dentários}

Estudos anteriores propuseram a presença de bactérias como responsável pela doença peri-implantar, mesmo em pacientes que apresentam uma adequada higiene oral. (Nascimento et al., Silva-Neto JP, 2012). Contudo, a presença de microorganismos não deve ser apontada como a única causa de falha em implantes dentários. Mombelli et al., (2011) apontaram as alterações de condições locais que podem favorecer o crescimento de bactérias patogênicas, levando á origem de doenças periimplantares. Segundo Baggi et al., (2013), a incidência da carga mastigatória e o afrouxamento do pilar protético podem levar à redução da estabilidade deste, favorecendo a infiltração bacteriana, influenciada pela sua geometria, precisão de conexão e o torque que foi utilizado para fixar os componentes.

A presença de gap está associada à uma intensa resposta inflamatória (Romanos et al., 2014), assim como o recrutamento de células 
inflamatórias entre a interface osso/implante resultantes da presença de micromovimentos, levando à uma contínua perda óssea (Harder, 2012).

Segundo Guindy et al. (2008), a infiltração bacteriana do meio ao interior do sistema de implantes foi observada dentro de 24-120 horas. No estudo in vitro, o sistema de conexão hexagonal foi testado através da presença Staphylococcus aureus, relatando que a passagem dos microorganismos ocorria tanto do meio para o interior do sistema quanto do interior para o meio, concluindo que a principal via de contaminação ocorria através do acesso do parafuso, mas que a presença de gap também apresentava uma importante relevância na penetração desses microorganismos.

Em 2011, Nascimento et al., compararam por meio de estudo a presença de infiltração bacteriana através da interface pilar/implante utilizando o método de cultura e a técnica de DNA Checkerboard. Trinta implantes com plataforma hexagonal foram conectados a pilares preusinados de acordo com especficação do fabricante e posteriormente incubados individualmente em saliva humana coletada por 7 dias à temperatura de $37^{\circ} \mathrm{C}$. Depois, o conteúdo da parte interna dos implantes foi coletada e avaliada com a técnica de DNA Checkerboard $(n=15)$ ou método de cultura $(n=15)$. Puderam observar através do estudo que tanto a técnica de DNA Checkerboard quanto o método de cultura convencional mostraram sinais positivos para infiltração bacteriana em 6 das 15 amostras avaliadas. A conclusão foi de que em ambas técnicas, DNA Checkerboard 
hibridização e método convencional de cultura, a ocorrência de infiltração bacteriana pode ser detectada.

No estudo de Martin-Gili et al. (2015), a presença de gaps foi analisada em dois tipos de conexões protéticas: externa e interna. Os testes foram realizados utilizando saliva artificial a $37^{\circ} \mathrm{C}$. O gap nas conexões foi mensurado através de um software de análise de imagens associado a um microscópio de alta resolução. A infiltração foi determinada por espectrometria de alta sensibilidade. No estudo, concluiu-se que conexões internas apresentaram menores gaps comparados aos resultados obtidos em pilares de conexão externa, um fator importante a ser levado em conta pelo implantodontista, já que a colonização bacteriana resultante da presença de gap na interface pilar/implante pode interferir na longevidade do tratamento reabilitador.

Theofilos Koutouzis et at. (2016), realizaram estudo in vitro para analisar o risco potencial de contaminação na interface pilar/implante por gaps em implantes dentais com design marginal inclinado. Vinte e quatro implantes foram divididos em dois grupos ( $n=20$ por Grupo) baseando-se no design marginal do implante. O Grupo 1 composto de implantes com conexão cone-morse e design marginal convencional conectados a pilares de titanio. O grupo 2 foi composto de implantes cone morse com design marginal inclinado conectados a pilares de titânio. As espécimes foram imersas em uma solução bacteriana de E. coli. Após a remoção dos componentes, amostras microbiológicas foram obtidas em condições apropriadas. Dez dos vinte implantes do Grupo 1 e oito dos vinte implantes 
do Grupo 2 tiveram gaps na interface pilar/implante colonizados por E. Coli.

O estudo relata que não houve diferença estatisticamente significante no número obtido de E. Coli detectado entre os diferentes tipos de implantes estudados, demonstrando que implantes com design marginal inclinado apresentam risco similar de contaminação na interface pilar/implante através de gaps comparado com implantes de design marginal convencional.

\subsection{DNA-Checkerboard como técnica de avaliação microbiológica}

Pesquisas clínicas para 0 embasamento e validação das investigações laboratoriais são difíceis de serem conduzidas para avaliação das áreas internas das conexões protéticas devido à inacessibilidade relativa aos procedimentos e métodos experimentais (Sakaguchi e Borgersen, 1993).

Adicionalmente, a maioria dos estudos avaliando a ocorrência de infiltração bacteriana através da interface implante/pilar protético utiliza métodos de cultura microbiana convencionais para detectar microorganismos aeróbios e anaeróbios. Um problema inerente com os métodos anaeróbios de cultura microbiana é que espécies que apresentam baixo potencial redox, portanto fastidiosas, podem não ser identificadas. Estima-se que aproximadamente $50 \%$ da microbiota oral não são cultiváveis pelos métodos convencionais (Socransky et al., 1963).

Por outro lado, as técnicas moleculares que fazem uso de material genético para identificação e quantificação de espécies de microorganismos colonizando a cavidade oral estão sendo frequentemente 
utilizadas em odontologia. São técnicas mais rápidas e sensíveis que se complementam. A técnica de hibridização DNA-Checkerboard possibilita a identificação e quantificação de um grande número de bactérias em um grande número de amostras simultaneamente. A técnica consiste no cruzamento das amostras de biofilme coletadas contra as sondas dos microorganismos a serem estudados, preparadas a partir de seu DNA genômico (Socransky et al., 1994; Nascimento et al., 2008).

A identificação destes microorganismos demonstra que a cavidade oral abriga quantidades relevantes de comunidades microbianas que podem ter papel importante na manutenção da saúde oral e sistêmica ou no desenvolvimento de doenças.

Com base nessa premissa, a metodologia proposta para $\circ$ presente estudo compreendeu a análise microbiológica pela técnica de hibridização DNA-Checkerboard, de diferentes interfaces implante/pilar em dois sistemas de conexão. 

3. Proposição 



\section{ProposiçÃo}

objetivo geral do presente do estudo foi avaliar microbiologicamente, por meio da técnica de hibridização DNA Checkerboard, a ocorrência de infiltração bacteriana do meio externo para o interior dos implantes através destas diferentes interfaces implante/pilar.

Como objetivos específicos foram avaliados dois diferentes sistemas de conexão de implantes, com parafusos de retenção de pilares planos convencionais e parafusos experimentais de forma cônica:

- Implante tipo Hexágono Externo (HE);

- Implante do tipo Triângulo Interno (TI). 

4. Xateriale Xétodos 



\section{MAterial e MÉtodos}

\subsection{Análises Microbiológicas}

\subsubsection{Seleção dos implantes}

Para o presente estudo, foram tilizados 48 implantes odontológicos osseointegráveis (DÉRIG ${ }^{\circledR}$, São Paulo, Brasil), 24 com conexão do tipo hexágono externo (HE) e 24 com conexão do tipo triângulo interno (TI), com seus respectivos pilares e parafusos protéticos convencionais e experimentais cônicos, corfome descritos na Tabela 1. 
Tabela 1. Dimensões dos implantes, pilares e parafusos.

\begin{tabular}{|c|c|}
\hline Componente & Especificações \\
\hline Implante Hexágono Externo & $\begin{array}{l}13,0 \mathrm{~mm} \text { comprimento } \\
3,75 \mathrm{~mm} \text { diâmetro } \\
4,1 \mathrm{~mm} \text { diâmetro plataforma } \\
0,70 \mathrm{~mm} \text { altura do hexágono } \\
2,70 \mathrm{~mm} \text { diâmetro do hexágono } \\
\text { Roscas externas } \mathrm{M} 3,75 \times 1,2 \mathrm{~mm} \text { (duas entradas) } \\
\text { Roscas internas tipo } \mathrm{M} 2,0 \times 0,4 \mathrm{~mm}\end{array}$ \\
\hline Implante Triângulo Interno & $\begin{array}{l}13,0 \mathrm{~mm} \text { comprimento } \\
4.3 \mathrm{~mm} \text { diâmetro } \\
4.3 \mathrm{~mm} \text { diâmetro plataforma } \\
1,4 \mathrm{~mm} \text { altura da porção cervical } \\
\text { Roscas externas } M 4,30 \times 0,65 \mathrm{~mm} \\
\text { Roscas internas } M 2,0 \times 0,4 \mathrm{~mm}\end{array}$ \\
\hline $\begin{array}{c}\text { Parafuso plano convencional } \\
\text { Hexágono Externo }\end{array}$ & $\begin{array}{l}2,45 \mathrm{~mm} \text { diâmetro cabeça } \\
\text { 1,60 mm altura cabeça } \\
\text { 7,10 mm comprimento total } \\
\text { 3,40 mm comprimento da seção rosqueada } \\
\text { 1,20 mm altura do encaixe para chave Unigrip } \\
\text { Roscas tipo } \mathrm{M} 2,0 \times 0,40 \mathrm{~mm}\end{array}$ \\
\hline $\begin{array}{c}\text { Parafuso plano convencional } \\
\text { Triângulo Interno }\end{array}$ & $\begin{array}{l}2,45 \mathrm{~mm} \text { diâmetro cabeça } \\
\text { 1,70 mm altura da cabeça } \\
\text { 9,40 mm comprimento total } \\
\text { 3,40 mm comprimento da seção rosqueada } \\
\text { 1,30 mm altura do encaixe para chave Unigrip } \\
\text { Roscas tipo } \mathrm{M} 2,0 \times 0,40 \mathrm{~mm}\end{array}$ \\
\hline $\begin{array}{c}\text { Parafuso experimental cônico } \\
\text { Hexágono Externo }\end{array}$ & $\begin{array}{l}2,45 \mathrm{~mm} \text { diâmetro da cabeça } \\
1,60 \mathrm{~mm} \text { altura cabeça } \\
25^{\circ} \text { angulação parte cônica cabeça } \\
7,10 \mathrm{~mm} \text { comprimento total } \\
3,40 \mathrm{~mm} \text { comprimento da seção rosqueada } \\
\text { 1,20 mm altura do encaixe para chave Unigrip } \\
\text { Roscas tipo M } 2,0 \times 0,40 \mathrm{~mm}\end{array}$ \\
\hline $\begin{array}{c}\text { Parafuso experimental cônico } \\
\text { Triângulo Interno }\end{array}$ & $\begin{array}{l}2,45 \mathrm{~mm} \text { diâmetro cabeça } \\
\text { 1,70 mm altura cabeça } \\
25^{\circ} \text { angulação parte cônica cabeça } \\
9,40 \mathrm{~mm} \text { comprimento total } \\
3,40 \mathrm{~mm} \text { comprimento da seção rosqueada } \\
\text { 1,30 mm altura do encaixe para chave Unigrip } \\
\text { Roscas tipo M 2,0 } 0 \text { 0,40 mm }\end{array}$ \\
\hline $\begin{array}{c}\text { Pilar Hexágono Externo } \\
\text { para parafuso convencional }\end{array}$ & $\begin{array}{l}11,70 \mathrm{~mm} \text { comprimento total } \\
2,60 \mathrm{~mm} \text { diâmetro do orifício para chave } \\
2,70 \mathrm{~mm} \text { diâmetro do hexágono } \\
4,1 \mathrm{~mm} \text { diâmetro externo da base } \\
5,0 \mathrm{~mm} \text { diâmetro da cinta } \\
3,0 \mathrm{~mm} \text { altura da cinta }\end{array}$ \\
\hline $\begin{array}{c}\text { Pilar Triângulo Interno } \\
\text { para parafuso convencional }\end{array}$ & $\begin{array}{l}\text { 14,10 mm comprimento total } \\
\text { 1 1,5 mm altura a partir da plataforma do implante } \\
2,60 \mathrm{~mm} \text { diâmetro do orifício para chave } \\
2,05 \mathrm{~mm} \text { diâmetro do triângulo } \\
4,3 \mathrm{~mm} \text { diâmetro externo da base } \\
\text { 4,7 mm diâmetro da cinta } \\
3,0 \mathrm{~mm} \text { altura da cinta }\end{array}$ \\
\hline $\begin{array}{c}\text { Pilar Hexágono Externo } \\
\text { para parafuso experimental } \\
\text { cônico }\end{array}$ & $\begin{array}{l}11,70 \mathrm{~mm} \text { comprimento total } \\
2,60 \mathrm{~mm} \text { diâmetro do orifício para chave } \\
2,70 \mathrm{~mm} \text { diâmetro do hexágono } \\
4,1 \mathrm{~mm} \text { diâmetro externo da base } \\
5,0 \mathrm{~mm} \text { diâmetro da cinta } \\
3,0 \mathrm{~mm} \text { altura da cinta } \\
25^{\circ} \text { angulação porção interna }\end{array}$ \\
\hline $\begin{array}{c}\text { Pilar Triângulo Interno } \\
\text { para parafuso experimental } \\
\text { cônico }\end{array}$ & $\begin{array}{l}\text { 14,10 mm comprimento total } \\
\text { 11,5 mm altura a partir da plataforma do implante } \\
2,60 \mathrm{~mm} \text { diâmetro do orifício para chave } \\
2,05 \mathrm{~mm} \text { diâmetro do triângulo } \\
\text { 4,3 mm diâmetro externo da base } \\
\text { 4,7 mm diâmetro da cinta } \\
3,0 \mathrm{~mm} \text { altura da cinta } \\
25^{\circ} \text { angulação porção interna }\end{array}$ \\
\hline
\end{tabular}


Esses implantes e componentes foram divididos em quatro grupos, da seguinte forma:

- Grupo 1: 12 conjuntos implantes HE + pilares e parafusos convencionais;

- Grupo 2: 12 conjuntos implantes HE + pilares e parafusos experimentais cônicos;

- Grupo 3: 12 conjuntos implantes TI + pilares e parafusos convencionais;

- Grupo 4: 12 conjuntos implantes TI + pilares e parafusos experimentais cônicos.

\subsubsection{Obtenção da Saliva}

Foram coletadas amostras de saliva e biofilme supragengival de cada 5 indivíduos adultos saudáveis. Os participantes foram selecionados dentre os pacientes da Faculdade de Odontologia de Ribeirão Preto - USP. Aos voluntários foi facultado o direito de decidir sobre sua participação ou não na fase experimental deste estudo durante o primeiro contato com os pesquisadores, e orientações foram dadas quanto aos procedimentos da pesquisa. As amostras de saliva foram coletadas imediatamente antes do teste de contaminação. O presente estudo foi realizado com a devida apreciação e aprovação do Comitê de Ética da Faculdade de Odontologia de Ribeirão Preto - USP - CAAE 29826714.6.0000.5419 - Plataforma Brasil: http://aplicacao.saude.gov.br/plataformabrasil/visao/ pesquisador/gerirPesquisa/gerirPesquisa.jsf (Anexo I). 
Na fase de recrutamento, foram incluídas pessoas de ambos os sexos, independente da faixa etária e que não apresentassem manifestações bucais de moléstias sistêmicas ou processos infecciosos agudos na cavidade oral. As coletas foram realizadas sempre no mesmo horário, além de se constituir um grupo de estudo com pessoas sob condições ambientais semelhantes, idades próximas, sob tipo de alimentação e cuidados semelhantes, a fim de se obter uma maior uniformidade da amostra de saliva, reduzindo com isso a variabilidade do estudo.

Todas as etapas microbiológicas do estudo foram realizadas em ambiente asséptico, livre da contaminação externa, em câmara de fluxo laminar e com bico de Bunsen. Toda a vidraria, pinças, torquímetro e chaves para torque foram previamente autoclavados. Os operadores foram devidamente paramentados com luvas cirúrgicas, gorros e máscaras esterilizadas. Foram coletados $2 \mathrm{~mL}$ de saliva não estimulada de cada indivíduo em microtubos.

Ao final das coletas, as amostras de saliva dos 5 indivíduos foram transferidas para um único tubo. Amostras do biofilme supra-gengival foram coletadas das faces lingual/palatina e labial dos primeiros molares superiores e inferiores de cada indivíduo com o auxílio de curetas e adicionadas aos 10 $\mathrm{mL}$ de saliva previamente coletados, procurando desta forma, aumentar a concentração de microorganismos na saliva. Após as coletas, o tubo contendo a saliva e biofilme bacteriano dos 5 pacientes foi homogeneizado 
durante 3 minutos e armazenado em estufa bacteriológica a $37^{\circ} \mathrm{C}$ até o início do teste de contaminação dos implantes.

\subsubsection{Teste de Contaminação}

Previamente à união dos implantes aos componentes protéticos, todos os componentes dos 4 grupos foram dispostos individualmente em envelopes grau cirúrgico e esterilizados em autoclave à temperatura de $121^{\circ} \mathrm{C}$ durante 30 minutos. Dentro de um fluxo laminar, os implantes foram retirados de suas embalagens, e em seguida, os pilares foram adaptados aos implantes com o auxílio da chave manual (DÉRIG ${ }^{\circledR}$, São Paulo, Brasil), (Figura 1), e o torque final dado com um torquímetro (DÉRIG ${ }^{\circledR}$, São Paulo, Brasil) como pode ser observado na (Figura 2), calibrado conforme instruções do fabricante. Os conjuntos implantes/pilares foram parcialmente imersos na solução de saliva humana em microtubos (Figura 3), restringindo-se a passagem dos microorganismos através da interface implante/pilar, e não através do parafuso de acesso oclusal. Os tubos foram incubados em $37^{\circ} \mathrm{C}$ durante 7 dias. 


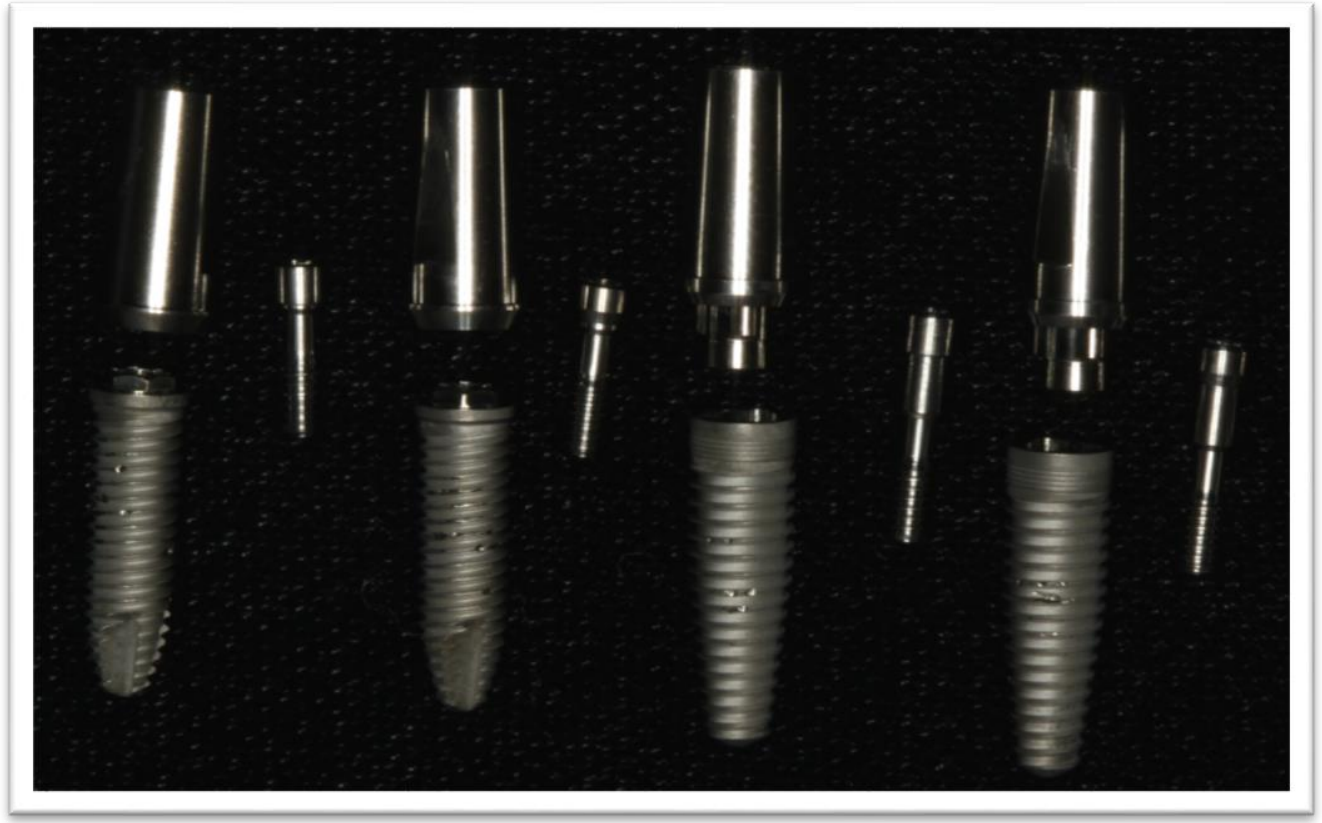

Figura1. Pilares, implantes e chave manual (DÉRIG ${ }^{\circledR}$, São Paulo, Brasil).

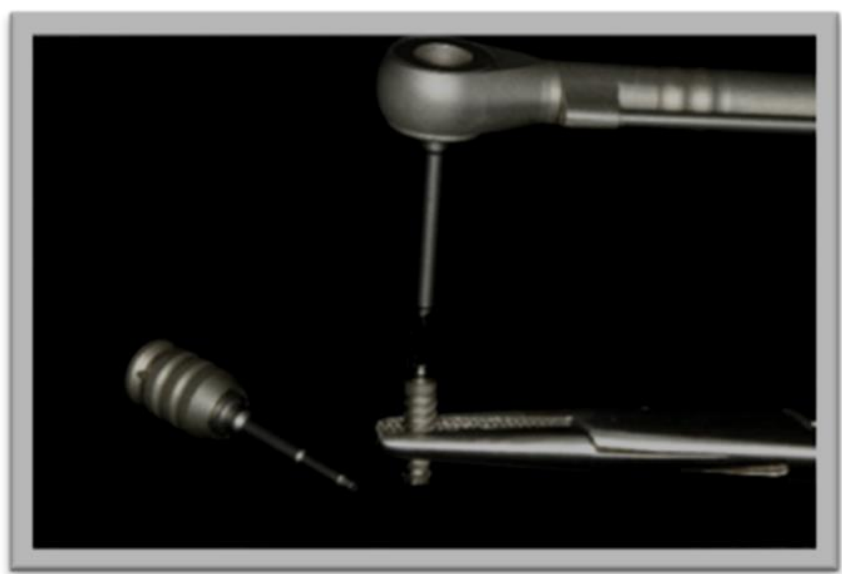

Figura 2. Torque final dado com um torquímetro (DÉRIG ${ }^{\circledR}$, São Paulo, Brasil).

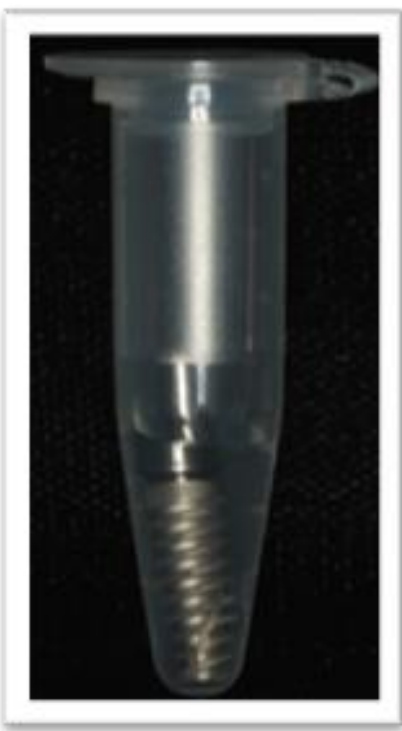

Figura 3. Conjunto Implante/Pilares Parcialmente imerso em solução de saliva humana em microtubos.

\subsubsection{Colheita das amostras}

Após o período de incubação, amostras do conteúdo interno dos conjuntos implantes/pilares dos 4 grupos foram colhidas com o objetivo de identificar e quantificar os micro-organismos presentes, utilizando para isto, a 
técnica de hibridização com sondas de DNA genômico DNA Checkerboard. Os implantes foram removidos dos tubos e lavados cuidadosamente com solução tampão salina fosfatada 0,1 M estéril $(\mathrm{pH}=7,0)$, e secados com gaze estéril.

Os implantes foram mantidos na posição vertical com o auxílio da pinça porta agulha, e todo o sistema foi reaberto no interior do fluxo laminar. O conteúdo do interior dos implantes e o material presente na superfície de seus respectivos parafusos foram colhidos com o auxílio de escovas do tipo microbrush (Figura 4). As amostras coletadas foram transferidas para

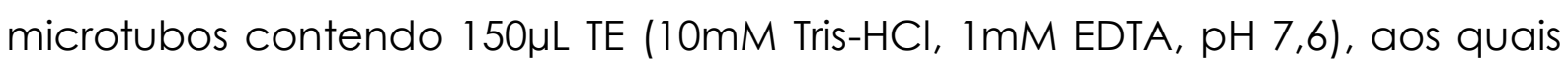
foram adicionados $150 \mu \mathrm{L}$ de $\mathrm{NaOH}$ 0,5M (Figura 5) para processamento pelo DNA Checkerboard. Todos os tubos foram armazenados a $-20^{\circ} \mathrm{C}$ até $\mathrm{O}$ processamento das amostras.

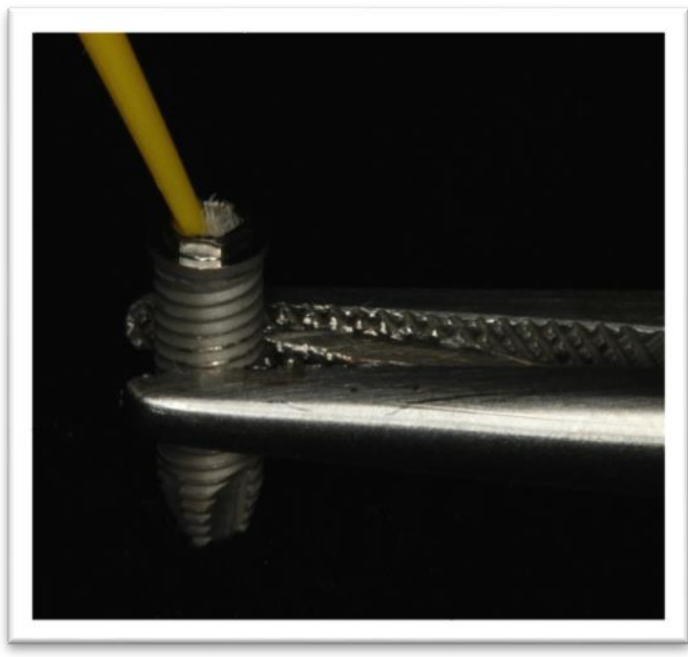

Figura 4. Remoção do conteúdo sendo colhido com o auxílio de escovas do tipo microbrush.

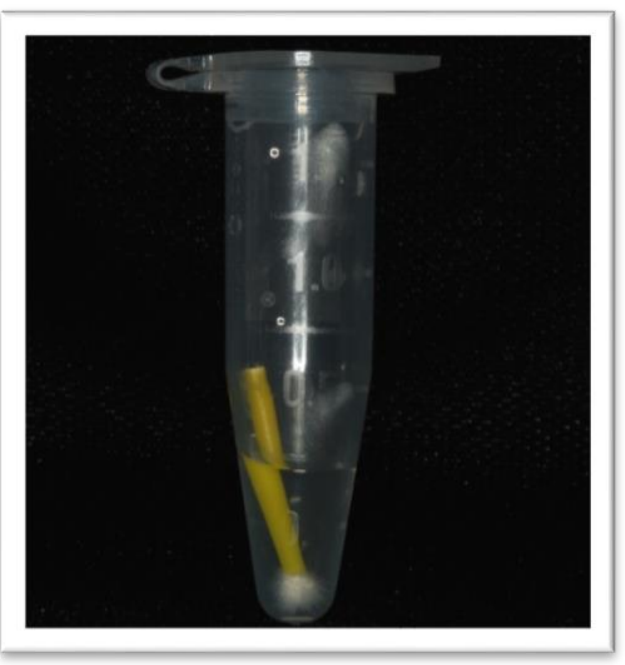

Figura 5. Amostra transferida para o microtubo para processamento. 


\subsubsection{Identificação e quantificação dos micro-organismos pelo método} de hibridização DNA Checkerboard

A análise das amostras pelo método da hibridização DNA Checkerboard foi realizada no Laboratório de Diagnóstico Odontológico Molecular (LabDom) do Departamento de Materiais Dentários e Prótese da Faculdade de Odontologia de Ribeirão Preto - USP, de acordo com do Nascimento et al. (2010). A ocorrência de infiltração microbiana através da interface implante-pilar no presente estudo foi avaliada por meio da técnica de hibridização DNA Checkerboard proposta por Socransky et al. (1994), com uma modificação de acordo com do Nascimento et al. (2010). Para tanto, foram selecionadas 35 espécies bacterianas, incluindo microorganismos patogênicos e não patogênicos, e 3 espécies de Candida spp., conforme disposto na Tabela 2. 
Tabela 2. Espécies microbianas (e seus respectivos números ATCC) utilizadas para a preparação das sondas de DNA alvo-específicas.

\begin{tabular}{|c|c|}
\hline Espécies Microbianas & Número ATCC \\
\hline Aggregatibacter actinomycetemcomitans a & 29523 \\
\hline Aggregatibacter actinomycetemcomitans b & 29522 \\
\hline Bacteroides fragilis & 25285 \\
\hline Capnocytophaga gingivalis & 33624 \\
\hline Campylobacter rectus & 33238 \\
\hline Escherichia coli & 10798 \\
\hline Eikenella corrodens & 23834 \\
\hline Enterococcus faecalis & 51299 \\
\hline Fusobacterium nucleatum & 25586 \\
\hline Fusobacterium periodonticum & 33693 \\
\hline Klebsiella pneumoniae & 700603 \\
\hline Lactobacilos casei & 393 \\
\hline Pseudomonas aeruginosa & 27853 \\
\hline Peptostreptococcus anaerobius & 27337 \\
\hline Porphyromonas endodontalis & 35406 \\
\hline Porphyromonas gingivalis & 33277 \\
\hline Prevotella intermedia & 25611 \\
\hline Prevotella melaninogenica & 25845 \\
\hline Parvimonas micra & 33270 \\
\hline Prevotella nigrescens & 25261 \\
\hline Pseudomonas putida & 12633 \\
\hline Staphylococcus aureus & 25923 \\
\hline Streptocuccus constellatus & 27823 \\
\hline Streptocuccus gordonii & 10558 \\
\hline Streptococcus mitis & 49456 \\
\hline Solobacterium moorei & CCUG39336 \\
\hline Streptococcus mutans & 25175 \\
\hline Streptococcus oralis & 35037 \\
\hline Streptococcus parasanguinis & 15911 \\
\hline Streptococcus salivarius & 25975 \\
\hline Streptococcus sanguinis & 10556 \\
\hline Streptococcus sobrinus & 27352 \\
\hline Treponema denticola & 35405 \\
\hline Tanerella forsythia & 43037 \\
\hline Veillonella parvula & 10790 \\
\hline Candida albicans & 10231 \\
\hline Candida dubliniensis & 44508 \\
\hline Candida krusei & 2159 \\
\hline
\end{tabular}




\subsection{Extração do DNA para a confecção das sondas dos micro-organismos}

As sondas foram preparadas a partir da extração do DNA genômico dos micro-organismos avaliados.

As soluções contendo o meio de cultura e os micro-organismos foram colocadas em tubos de $50 \mathrm{~mL}$ para centrifugação a 13200 rpm por 15 minutos, e obtenção dos pellets. Os pellets foram removidos e colocados em um tubo Eppendorf. Foram acrescentados $500 \mu \mathrm{L}$ de GES (tiocianato de guanidina, EDTA e Sarkosyl 30\%).

Quando as células estavam completamente lisadas, foram adicionados $250 \mu \mathrm{L}$ de acetato de amônio e os tubos foram colocados no gelo por 10 minutos. Após este procedimento, foram adicionados $500 \mu \mathrm{L}$ de clorofórmio/2-pentanol, seguido de agitação vigorosa por 10 minutos, para misturar as duas fases. O conteúdo foi centrifugado por 10 minutos a 13.200 rpm para formar um tampão na interface das soluções. A solução da parte superior do tubo foi removida cuidadosamente e colocada em outro tubo Eppendorf com $875 \mu \mathrm{L}$ de etanol $100 \%$ gelado, onde permaneceu a $-20^{\circ} \mathrm{C}$ durante a noite (overnight).

Após este período as fibras de DNA formadas foram removidas e colocadas em etanol $70 \%$ gelado, e então armazenadas a $-20^{\circ} \mathrm{C}$.

\subsection{Purificação e quantificação do DNA}

Os tubos contendo as fibras foram levados à centrífuga a 13200 rpm por 1 minuto. A solução sobrenadante foi removida e $1 \mathrm{~mL}$ de etanol $70 \%$ foi acrescentado. As fibras foram lavadas com etanol $70 \%$ até a 
remoção dos excessos de sais e carboidratos. Após a lavagem, todo o álcool e o excesso foram removidos com o auxílio de papel absorvente. Foram acrescentados $100 \mu \mathrm{L}$ de TE $(\mathrm{pH} 8,0)$ e o tubo foi armazenado a $4^{\circ} \mathrm{C}$ até entrar em solução. Após entrar em solução, o procedimento de lavagem foi completado acrescentando-se $100 \mu \mathrm{L}$ de clorofórmio/álcool isoanídrico.

O tratamento de purificação do DNA foi concluído com a adição da RNase. Em um tubo Eppendorf de 1,5 mL, foram colocados $5 \mu \mathrm{L}$ do microorganismo com $95 \mu \mathrm{L}$ de RNase $20 \mu \mathrm{g} / \mathrm{mL}$, por 30 minutos. Após o processo de extração e limpeza, o DNA foi ressuspendido em TE para análise em gel de agarose, além de quantificação e verificação do grau de pureza no espectrofotômetro GeneQuant pro (Amersham Pharmacia Biotech, UK).

\subsection{Marcação das sondas}

O protocolo utilizado para a marcação do DNA dos microorganismos foi aquele estabelecido pela empresa fabricante do marcador genômico (Gene Images Alkphos Direct labelling and Detection System, GE Healthcare, UK). O protocolo baseia-se na marcação de 100 ng do DNA genômico do micro-organismo a ser estudado, atingindo uma concentração final de $1 \mathrm{ng} / \mu \mathrm{L}$ na solução de hibridização. O DNA foi diluído dentro de tubos Eppendorf de 0,5 mL e desnaturado em água fervente por 5 minutos. Imediatamente, foram resfriados em gelo para manter as cadeias de nucleotídeos abertas. Foram então acrescentados os componentes do kit de marcação e os tubos incubados a $37^{\circ} \mathrm{C}$ por 30 minutos. 


\subsection{Teste de sensibilidade e especificidade das sondas dos micro- organismos}

A sensibilidade do teste foi ajustada para permitir a observação de reações de hibridização positivas para a presença de $10^{5}$ e $10^{6}$ células bacterianas, de acordo com a quantidade de sonda usada.

\subsection{Processamento das amostras}

Os tubos contendo as amostras foram descongelados à temperatura ambiente. Com o auxílio de um agitador de tubos (AP 56, Phoenix, Brasil,), os tubos foram agitados por 4 minutos para a desagregação total do conteúdo colhido pela escova microbrush (Figura 6). Ao final do período de agitação, a ponta da escova foi removida com o auxílio de uma pinça clínica esterilizada. Os tubos foram fervidos em banho-maria por 5 minutos para a separação das fitas de DNA, e logo resfriados em gelo. Após a fervura, as suspensões foram neutralizadas com a adição de $800 \mu \mathrm{L}$ de acetato de amônio 5M, o que levou à precipitação do DNA na solução.

Uma placa metálica denominada Minislot 30 (Immunetics, EUA) contém 30 canaletas dispostas paralelamente, e foi utilizada para a aplicação das amostras sobre a membrana de nylon Hybond N+ (Figura 7), disposta dentro do aparelho. A membrana tem carga positiva e deve medir $15 \times 15 \mathrm{~cm}$, cobrindo desta forma todo o comprimento das canaletas. 0 aparelho permite a deposição de 28 diferentes amostras em canaletas individuais, bem como duas canaletas contendo os controles $10^{5}$ e $10^{6}$ de cada espécie estudada. Cada solução contendo o DNA livre foi depositada 
no interior das canaletas, e após 5 minutos da aplicação, o DNA foi depositado na membrana de nylon com o auxílio do vácuo. A membrana foi removida do aparelho e o DNA fixado na membrana a $80^{\circ} \mathrm{C}$ durante 2 horas.

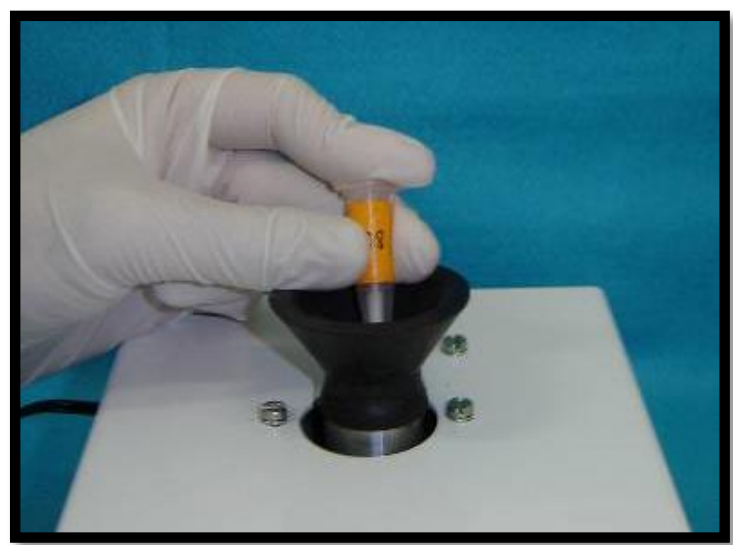

Figura 6. Tubos agitados por 4 minutos para a desagregação do conteúdo colhido pela escova.

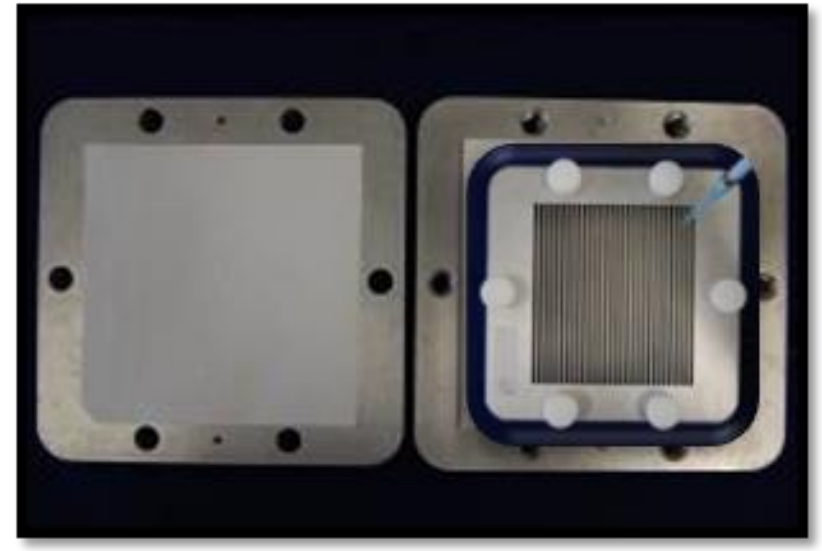

Figura 7. Aplicação das amostras sobre a membrana nylon Hybond $\mathrm{N}+$.

\subsection{Aplicação das sondas e reação de hibridização}

Previamente à aplicação das sondas, a membrana foi submetida a um procedimento de pré-hibridização (Hybridization buffer, $\mathrm{NaCl} 0,5 \mathrm{M} e$ Reagent blocking 4\%). Após a pré-hibridização, a membrana foi colocada no Miniblotter 45 (Immunetics, USA, Figura 8), com as linhas contendo o DNA fixado das amostras perpendiculares às canaletas do aparelho. As canaletas do Miniblotter 45 foram preenchidas com $150 \mu \mathrm{L}$ de sonda de cada microorganismo avaliado. As canaletas onde não foram aplicadas as sondas foram preenchidas com $150 \mu \mathrm{L}$ da solução de hibridização. Após a aplicação das sondas, o aparelho foi embrulhado várias vezes em filme de PVC, e embalado em saco plástico, evitando a desidratação das membranas. A hibridização da membrana foi realizada no forno de hibridização a $55^{\circ} \mathrm{C}$ overnight. 


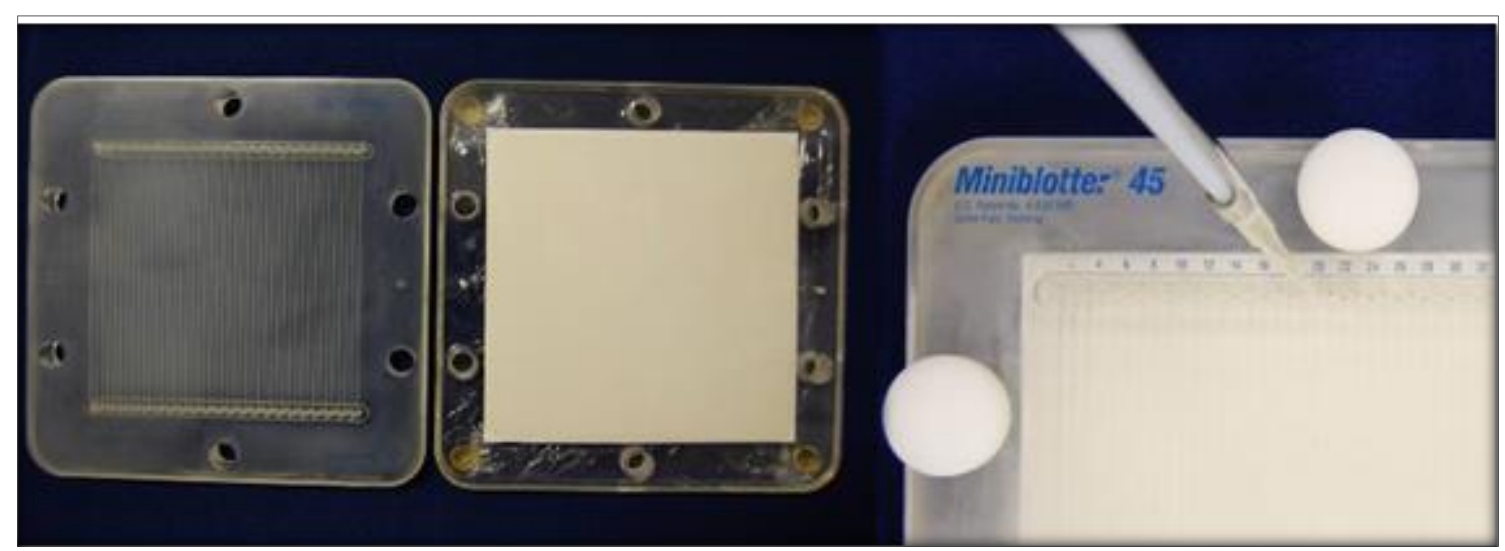

Figura 8. Membrana posicionada no Miniblotter $45 \mathrm{com}$ as linhas contendo o DNA fixado das amostras perpendiculares às canaletas do aparelho.

\subsection{Detecção dos sinais de hibridização}

Após a reação de hibridização, a membrana passou por um processo de lavagem e detecção dos sinais. Após as lavagens, foram aplicados 6,7 mL do reagente de detecção CDP-Star ${ }^{\circledR}$ (GE Healthcare, UK) sobre a membrana, deixando-o agir em toda a superfície da membrana por 5 minutos. Após este período, o excesso do reagente foi removido e a membrana embalada em saco plástico. A membrana foi exposta a um filme radiográfico utilizando um cassete de exposição Hypercassete (GE Healthcare, UK). Dentro de uma câmara escura, a membrana é colocada no interior do cassete, e sobre ela é posicionado um filme radiográfico Hyperfilm (GE Healthcare, UK), como ilustra a Figura 9. A exposição ocorreu durante uma hora, seguindo-se o procedimento de revelação para a detecção dos sinais de quimioluminescência.

Ao final, obteve-se um filme radiográfico com os sinais detectados pelas sondas de DNA, onde as linhas horizontais representam as sondas, e as verticais representam as amostras dos implantes (Figura 10), configurando desta forma um "tabuleiro de xadrez" (checkerboard). 


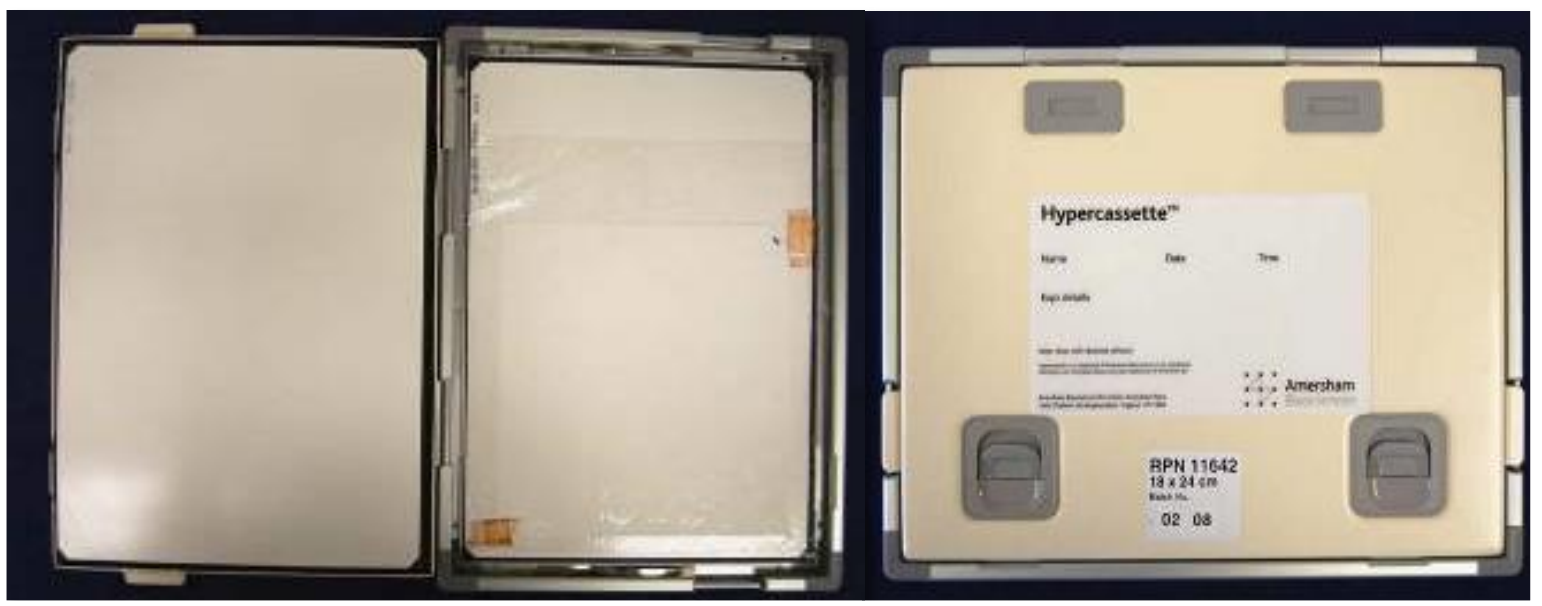

Figura 9. Membrana posicionada no interior do cassete, e sobre ela posicionado o filme radiográfico Hyperfilm (GE Healthcare, UK).

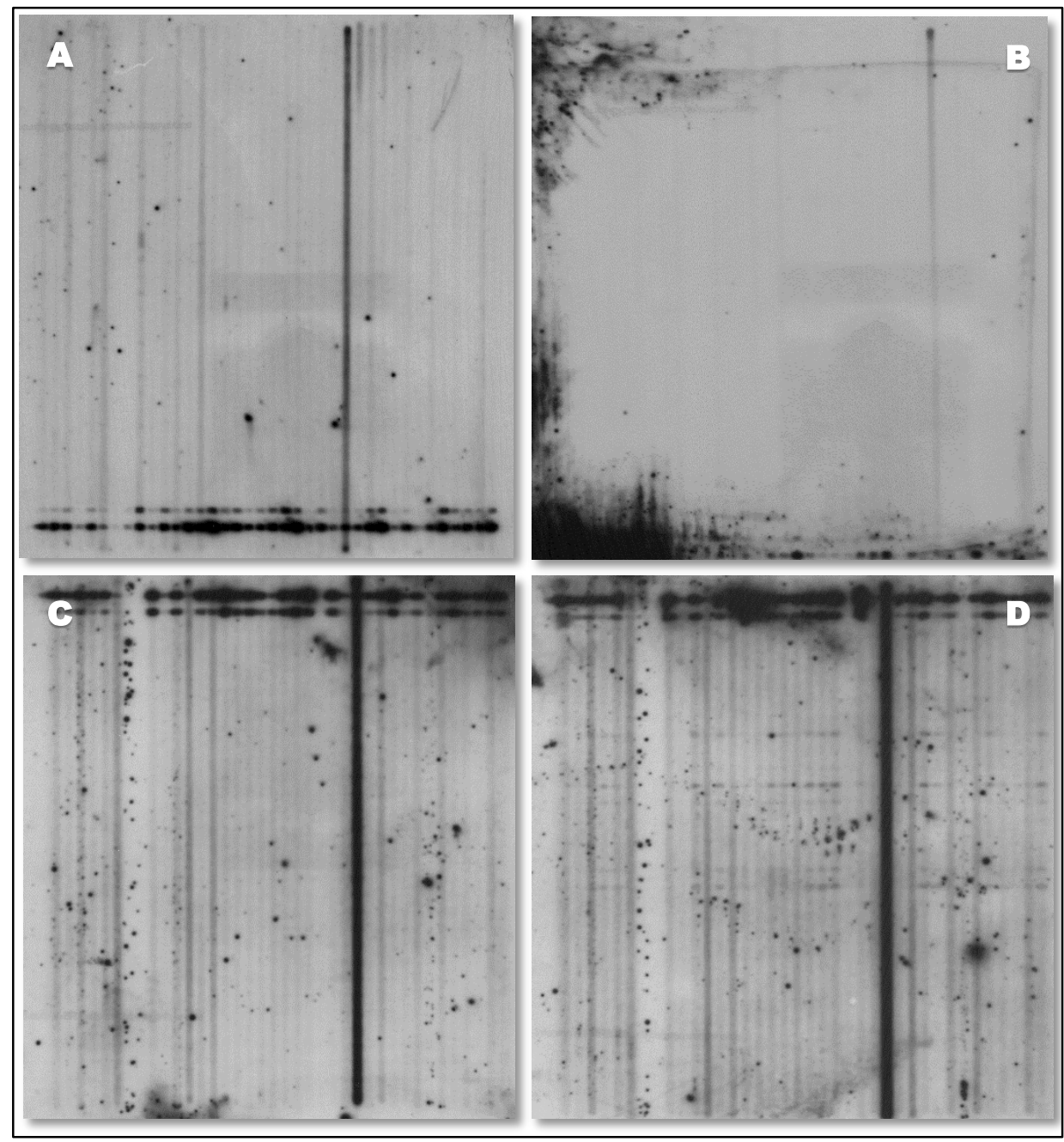

Figura 10. Membranas após exposição radiográfica, ilustrando o Grupol (A), Grupo 2 (B), Grupo 3 (C) e grupo 4 (D). 


\subsection{Interpretação dos sinais}

A leitura dos resultados é semi-quantitativa, feita por meio da comparação visual dos sinais das amostras com os do controle, feitos a partir do DNA da bactéria que foi pesquisada, e colocada nas duas últimas canaletas do Minislot 30, que equivalem a $10^{5}$ e $10^{6}$ células.

Tipicamente, os sinais devem ser registrados como 0: não detectado; 1: < 105 células; 2: 105; 3: 105 106; 4: 106; e 5: > 106 células (Socransky et al. 2004). Desta forma, um número aproximado de células bacterianas em cada amostra é obtido. A confirmação da análise visual é feita pela avaliação da intensidade de pixels dos sinais por meio do software Total Lab Quant (GE Healthcare, UK). 
5. Resultados 



\section{RESULTADOS}

\subsection{Forma de análise dos resultados}

Os resultados obtidos a partir das análises microbiológicas foram avaliados por meio de comparações das médias ou medianas dos grupos de implantes/conexões estudados empregando-se os testes adequados, de acordo com a sua distribuição. Os dados obtidos (número de células bacterianas) foram submetidos à análise de variância. De acordo com a distribuição dos dados amostrais foi escolhido o teste estatístico mais apropriado para a análise dos dados, considerando um intervalo de confiança de 95\%, ou ainda valor de $p$ menor ou igual a $0,05(p \leq 0,05)$.

Não houve sinais positivos de contaminação microbiana nas interfaces implantes-pilares utilizadas como controles negativos. A ausência de sinais de hibridização evidencia que os grupos testados não foram contaminados antes da etapa de incubação.

A presença de infiltração microbiana por meio da interface implante-pilar foi detectada pela técnica de hibridização DNA Checkerboard em 3 das 4 conexões avaliadas. Após 7 dias de incubação dos corpos de prova em saliva humana, os conjuntos do grupo formado pela conexão HE com parafusos convencionais $(G 1)$ e os conjuntos de ambos os grupos formados pela conexão Tl, com parafusos planos convencionais (G3) e com parafusos experimentais cônicos (G4), apresentaram sinais de colonização microbiana nas superfícies internas dos implantes. Nenhuma das 
amostras coletadas do grupo HE com parafusos experimentais cônicos (G2) foram positivos para as sondas de DNA testadas.

A média ( \pm DP), a mediana, o menor e o maior quartil das contagens de genomas microbianos (×104 células) das 38 espécies-alvo e os seus respectivos valores de p são apresentados na Tabela 3. 
Tabela 3. Média, mediana, menor e maior quartil das contagens microbianas (x104 \pm DP) e seus respectivos valores de $p$, avaliados pela técnica de hibridização DNA Checkerboard nos grupos testados.

\begin{tabular}{|c|c|c|c|c|c|c|c|c|c|c|c|c|c|c|c|c|c|c|c|c|c|}
\hline & \multirow[b]{3}{*}{ Média } & \multirow{2}{*}{\multicolumn{3}{|c|}{$\begin{array}{c}\text { GRUPO 1 } \\
\text { HE - Convencional } \\
\end{array}$}} & \multirow[b]{3}{*}{$\begin{array}{c}\text { Maior } \\
\text { quartil }\end{array}$} & \multirow[b]{3}{*}{ Média } & \multirow[b]{3}{*}{$\pm \mathrm{DP}$} & \multirow{2}{*}{\multicolumn{2}{|c|}{$\begin{array}{l}\text { GRUPO } 2 \\
\text { HE - Experimental } \\
\end{array}$}} & \multirow[b]{3}{*}{$\begin{array}{l}\text { Maior } \\
\text { quartil }\end{array}$} & \multirow{2}{*}{\multicolumn{4}{|c|}{$\begin{array}{c}\text { GRUPO } 3 \\
\mathrm{TI}-\mathrm{CC} \mathrm{TI}-\text { Convencional } \\
\end{array}$}} & \multirow[b]{3}{*}{$\begin{array}{l}\text { Maior } \\
\text { quartil }\end{array}$} & \multirow[b]{3}{*}{ Média } & \multirow{2}{*}{\multicolumn{3}{|c|}{\begin{tabular}{|l|} 
GRUPO 4 \\
TI - Experimental \\
\end{tabular}}} & \multirow[b]{3}{*}{$\begin{array}{l}\text { Maior } \\
\text { quartil }\end{array}$} & \multirow[b]{3}{*}{$\begin{array}{c}\text { valores } \\
\text { de } p\end{array}$} \\
\hline & & & & & & & & & & & & & & & & & & & & & \\
\hline & & $\pm \mathrm{DP}$ & $\begin{array}{l}\text { Menor } \\
\text { quartil }\end{array}$ & Mediana & & & & $\begin{array}{l}\text { Menor } \\
\text { quartil }\end{array}$ & Mediana & & Média & $\pm \mathrm{DP}$ & $\begin{array}{l}\text { Menor } \\
\text { quartil } \\
\end{array}$ & Mediana & & & $\pm D P$ & $\begin{array}{l}\text { Menor } \\
\text { quartil }\end{array}$ & Mediana & & \\
\hline Aa a & 0 & 0 & 0 & 0 & 0 & 0 & 0 & 0 & 0 & 0 & 0 & 0 & 0 & 0 & 0 & 0.09 & 0.33 & 0 & 0 & 0 & 0.3916 \\
\hline$A a b$ & 0 & 0 & 0 & 0 & 0 & 0 & 0 & 0 & 0 & 0 & 3.13 & 7.32 & 0 & 0 & 0 & 0.28 & 0.91 & 0 & 0 & 0.06 & 0.1278 \\
\hline C. gingivalis & 0 & 0 & 0 & 0 & 0 & 0 & 0 & 0 & 0 & 0 & 0 & 0 & 0 & 0 & 0 & 0 & 0 & 0 & 0 & 0 & $>0.05$ \\
\hline C. rectus & 0 & 0 & 0 & 0 & 0 & 0 & 0 & 0 & 0 & 0 & 0 & 0 & 0 & 0 & 0 & 0 & 0 & 0 & 0 & 0 & $>0.05$ \\
\hline E. coli & 0 & 0 & 0 & 0 & 0 & 0 & 0 & 0 & 0 & 0 & 0 & 0 & 0 & 0 & 0 & 0.02 & 0.09 & 0 & 0 & 0 & 0.3916 \\
\hline E. faecalis & 0 & 0 & 0 & 0 & 0 & 0 & 0 & 0 & 0 & 0 & 0 & 0 & 0 & 0 & 0 & 0.41 & 1.42 & 0 & 0 & 0 & 0.3916 \\
\hline F. nucleatum & 0 & 0 & 0 & 0 & 0 & 0 & 0 & 0 & 0 & 0 & 0 & 0 & 0 & 0 & 0 & 0 & 0 & 0 & 0 & 0 & $>0.05$ \\
\hline L. casei & 0 & 0 & 0 & 0 & 0 & 0 & 0 & 0 & 0 & 0 & 0 & 0 & 0 & 0 & 0 & 0 & 0 & 0 & 0 & 0 & $>0.05$ \\
\hline P. anaerobios * & 0 & 0 & 0 & 0 & 0 & 0 & 0 & 0 & 0 & 0 & 0 & 0 & 0 & 0 & 0 & 1.37 & 2.48 & 0 & 0 & 0 & 0.0010 \\
\hline P. gingivalis & 0 & 0 & 0 & 0 & 0 & 0 & 0 & 0 & 0 & 0 & 3.42 & 8.00 & 0 & 0 & 0 & 1.24 & 2.92 & 0 & 0 & 0 & 0.2330 \\
\hline P. intermedia & 0 & 0 & 0 & 0 & 0 & 0 & 0 & 0 & 0 & 0 & 0 & 0 & 0 & 0 & 0 & 0 & 0 & 0 & 0 & 0 & $>0.05$ \\
\hline P. melaninogenica* & 0 & 0 & 0 & 0 & 0 & 0 & 0 & 0 & 0 & 0 & 41.16 & 4.92 & 38.25 & 41.21 & 43.53 & 0 & 0 & 0 & 0 & 0 & $<0.0001$ \\
\hline P. micra & 0 & 0 & 0 & 0 & 0 & 0 & 0 & 0 & 0 & 0 & 0 & 0 & 0 & 0 & 0 & 0 & 0 & 0 & 0 & 0 & $>0.05$ \\
\hline P. nigrescens & 0 & 0 & 0 & 0 & 0 & 0 & 0 & 0 & 0 & 0 & 0 & 0 & 0 & 0 & 0 & 1.23 & 4.26 & 0 & 0 & 0 & 0.3916 \\
\hline P. putida & 0 & 0 & 0 & 0 & 0 & 0 & 0 & 0 & 0 & 0 & 0 & 0 & 0 & 0 & 0 & 0 & 0 & 0 & 0 & 0 & $>0.05$ \\
\hline S. aureus & 1.15 & 3.98 & 0 & 0 & 0 & 0 & 0 & 0 & 0 & 0 & 1.68 & 5.85 & 0 & 0 & 0 & 0.70 & 2.17 & 0 & 0 & 0 & 0.5795 \\
\hline S. gordonii & 0 & 0 & 0 & 0 & 0 & 0 & 0 & 0 & 0 & 0 & 1.74 & 6.03 & 0 & 0 & 0 & 1.98 & 4.61 & 0 & 0 & 0 & 0.1052 \\
\hline S. mitis & 0 & 0 & 0 & 0 & 0 & 0 & 0 & 0 & 0 & 0 & 1.73 & 6.01 & 0 & 0 & 0 & 1.85 & 5.19 & 0 & 0 & 0 & 0.2941 \\
\hline S. moorei & 0 & 0 & 0 & 0 & 0 & 0 & 0 & 0 & 0 & 0 & 1.71 & 5.93 & 0 & 0 & 0 & 0.35 & 0.89 & 0 & 0 & 0 & 0.2941 \\
\hline S. mutans & 0 & 0 & 0 & 0 & 0 & 0 & 0 & 0 & 0 & 0 & 1.70 & 5.91 & 0 & 0 & 0 & 0.82 & 2.21 & 0 & 0 & 0 & 0.2941 \\
\hline S. sanguinis & 0.56 & 1.95 & 0 & 0 & 0 & 0 & 0 & 0 & 0 & 0 & 1.41 & 4.90 & 0 & 0 & 0 & 0 & 0 & 0 & 0 & 0 & 0.5633 \\
\hline T. forsythia & 0 & 0 & 0 & 0 & 0 & 0 & 0 & 0 & 0 & 0 & 3.20 & 7.49 & 0 & 0 & 0 & 0 & 0 & 0 & 0 & 0 & 0.1056 \\
\hline T. denticola & 0 & 0 & 0 & 0 & 0 & 0 & 0 & 0 & 0 & 0 & 0 & 0 & 0 & 0 & 0 & 0 & 0 & 0 & 0 & 0 & $>0.05$ \\
\hline V. parvula & 0 & 0 & 0 & 0 & 0 & 0 & 0 & 0 & 0 & 0 & 0 & 0 & 0 & 0 & 0 & 0.22 & 0.59 & 0 & 0 & 0 & 0.1056 \\
\hline S. parasanguinis & 0 & 0 & 0 & 0 & 0 & 0 & 0 & 0 & 0 & 0 & 0 & 0 & 0 & 0 & 0 & 0 & 0 & 0 & 0 & 0 & $>0.05$ \\
\hline S. sobrinus & 0 & 0 & 0 & 0 & 0 & 0 & 0 & 0 & 0 & 0 & 0 & 0 & 0 & 0 & 0 & 0.83 & 2.87 & 0 & 0 & 0 & 0.1056 \\
\hline B. fragilis & 0 & 0 & 0 & 0 & 0 & 0 & 0 & 0 & 0 & 0 & 0 & 0 & 0 & 0 & 0 & 0 & 0 & 0 & 0 & 0 & $>0.05$ \\
\hline K. pneumoniae & 0 & 0 & 0 & 0 & 0 & 0 & 0 & 0 & 0 & 0 & 3.38 & 7.92 & 0 & 0 & 0 & 0.13 & 0.38 & 0 & 0 & 0 & 0.2330 \\
\hline S. constellatus & 0 & 0 & 0 & 0 & 0 & 0 & 0 & 0 & 0 & 0 & 0 & 0 & 0 & 0 & 0 & 0.14 & 0.49 & 0 & 0 & 0 & 0.3916 \\
\hline E. corrodens & 0 & 0 & 0 & 0 & 0 & 0 & 0 & 0 & 0 & 0 & 0 & 0 & 0 & 0 & 0 & 0 & 0 & 0 & 0 & 0 & $>0.05$ \\
\hline F. periodonticum & 0 & 0 & 0 & 0 & 0 & 0 & 0 & 0 & 0 & 0 & 0 & 0 & 0 & 0 & 0 & 0.85 & 2.95 & 0 & 0 & 0 & 0.3916 \\
\hline P. endodontalis & 0 & 0 & 0 & 0 & 0 & 0 & 0 & 0 & 0 & 0 & 0 & 0 & 0 & 0 & 0 & 0 & 0 & 0 & 0 & 0 & $>0.05$ \\
\hline S. oralis & 0 & 0 & 0 & 0 & 0 & 0 & 0 & 0 & 0 & 0 & 0 & 0 & 0 & 0 & 0 & 1.25 & 4.33 & 0 & 0 & 0 & 0.3916 \\
\hline C. albicans & 0 & 0 & 0 & 0 & 0 & 0 & 0 & 0 & 0 & 0 & 0 & 0 & 0 & 0 & 0 & 0 & 0 & 0 & 0 & 0 & $>0.05$ \\
\hline C. dubliniensis * & 8.73 & 8.42 & 0 & 7.73 & 13.35 & 0 & 0 & 0 & 0 & 0 & 0 & 0 & 0 & 0 & 0 & 0 & 0 & 0 & 0 & 0 & $<0.0001$ \\
\hline c. krusei & 0 & 0 & 0 & 0 & 0 & 0 & 0 & 0 & 0 & 0 & 0 & 0 & 0 & 0 & 0 & 0 & 0 & 0 & 0 & 0 & $>0.05$ \\
\hline
\end{tabular}

*Espécies com diferenças entre os grupos testados, detectados pelo teste de múltiplas comparações de Dunn (p<0.05). 
O método de equações estimativas generalizadas (EEG) mostrou diferenças significativas comparando as medianas de cada espécie-alvo entre os diferentes grupos $(p<0,0001)$. Peptostreptococcos anaeróbios $(p=$ $0,0010)$, Prevotella melaninogenica ( $p<0,0001$ ) e Candida dubliniensis ( $p<$ 0,0001) foram as únicas espécies que apresentam diferenças significativas, comparando os diferentes grupos (teste de múltiplas comparações de Bonferroni).

No geral, níveis baixos a moderados de contaminação (variando de $0,09 \pm 0,33$ para $8,73 \pm 8,42$ ) foram registrados para 24 das 38 espéciesalvo testadas. Os valores médios mais altos ( $\times 104$ células, \pm DP) de contagem de genomas foram registrados para $P$. melaninogenica $(41,16 \pm 4,92)$ em amostras do grupo 3 (TI com parafuso convencional). O grupo 4 (TI com parafuso experimental) apresentou a maior taxa de detecção de espéciesalvo (20 de 38). As outras taxas de detecção foram registradas da seguinte forma: G1 (3 de 38), G2 (0 de 38) e G3 (13 de 38). Não foram encontradas diferenças significativas comparando espécies diferentes dentro do mesmo grupo $(p=0,7402)$.

A contagem total de genomas microbianos foi fornecida pela avaliação de um conjunto de todas as 38 espécies microbianas testadas para cada grupo. O Gráfico 1 ilustra as medianas com intervalo interquartil da contagem total de genomas dos grupos avaliados, independentemente da distinção entre as espécies. Foram encontradas diferenças significativas entre as medianas (teste de Kruskal-Wallis; $p<0,0001$ ). O teste de Bonferroni mostrou que as conexões TI (G3 e G4) apresentaram contagens mais 
elevadas quando comparadas com as conexões HE (G1 e G2; $p<0,01$ ). No entanto, não foram encontradas diferenças significativas entre as comparações dentro da mesma conexão $(p>0,05)$. As médias das contagens totais ( \pm DP) para cada grupo foram: $G 1(0,27 \pm 2,04), G 2(0 \pm 0)$, G3 $(1,81 \pm 7,50)$ e $G 4(0,35 \pm 1,81)$.

Para a análise de prevalência, os valores de p foram de 0,0086 (para grupos) e de 0,6966 (para as espécies-alvo). P. melaninogenica e C. dubliniensis mostraram diferenças significativas entre os grupos testados (teste de Bonferroni; $p<0,01$ ). No geral, os maiores valores de prevalência foram registrados para $P$. melaninogenica (100\%) no G3, seguido de C. dubliniensis no G1 (66,66\%).

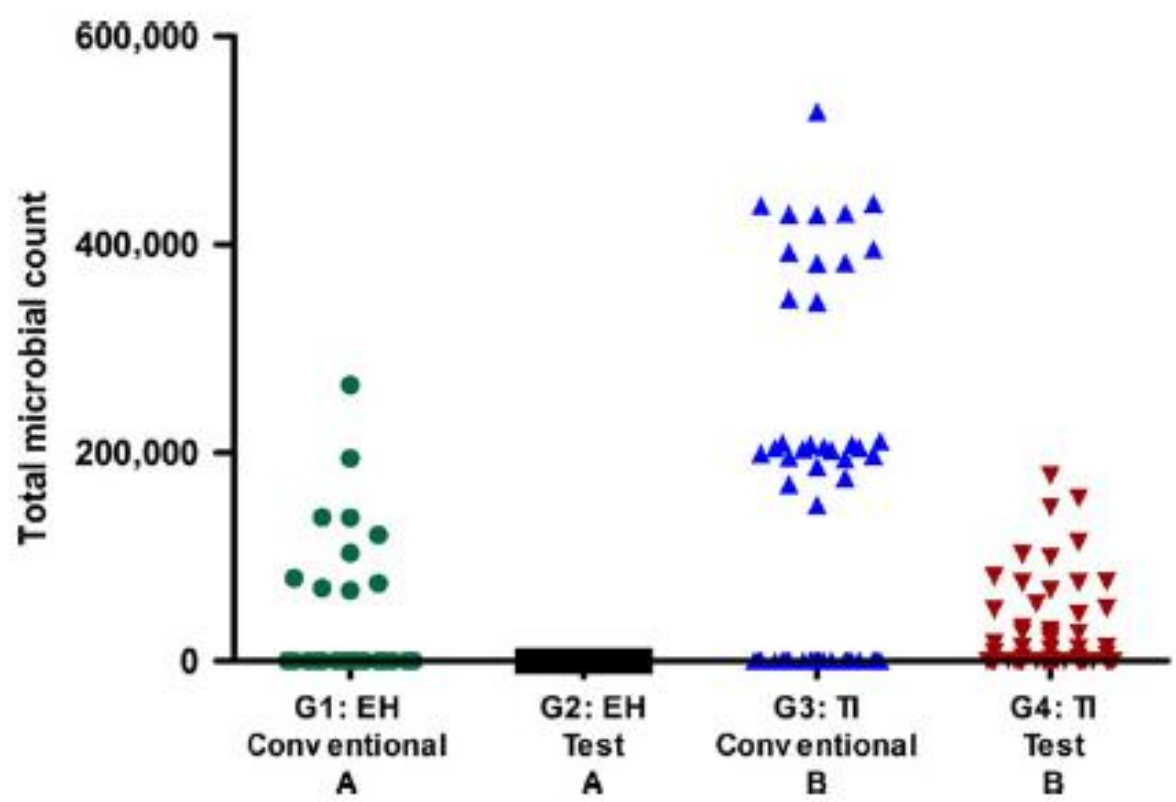

Gráfico 1. Scatter da contagem de genoma microbiano total, com mediana e intervalo interquartil para grupos testados (As diferentes letras significam diferenças significativas detectadas pelo teste de Kruskal-Wallis, seguido de comparações múltiplas de Bonferroni pós-testes; $\mathrm{A}<\mathrm{B} \mathrm{P}<0,01$ ). 




\section{DISCUSSÃO}

O objetivo deste estudo foi avaliar o impacto de duas diferentes geometrias de parafusos de fixação de pilares protéticos sobre a infiltração microbiana pela interface implante-pilar, em conexões de hexágono externo (HE) e triângulo interno (TI). Para tanto, foram testados parafusos planos convencionais bem como parafusos experimentais cônicos, em ambas conexões.

A análise microbiológica pela técnica DNA Checkerboard foi realizada para identificar e quantificar as 38 espécies microbianas testadas colonizando as superfícies internas dos implantes, incluindo agentes patogênicos, não-patogênicos, e espécies oportunistas comumente encontradas no biofilme bucal.

A hipótese nula testada nesta condição experimental foi confirmada. Diferentes parafusos de retenção de pilares e conexões protéticas influenciaram na infiltração microbiana por meio da interface implante-pilar. A maioria das espécies-alvo (24 de 38 ) foram encontradas colonizando as superfícies internas dos implantes após 7 dias de incubação em saliva humana.

Os conjuntos dos grupos $\mathrm{Tl}$, tanto os fixados com parafusos convencionais quanto os experimentais, apresentaram espécies colonizando as superfícies internas dos implantes. No grupo HE, apenas os conjuntos fixados com parafusos convencionais apresentaram contaminação microbiana. No geral, as conexões HE e TI registraram valores semelhantes de contagem microbiana individual, sem diferenças significativas entre os 
grupos, com exceção da P. melaninogenica, P. anaerobius e C. dubliniensis, que foram registradas em níveis mais elevados nos grupos G3, G4 e G1, respectivamente.

Quando a contagem microbiana total foi processada, independentemente da distinção entre as espécies-alvo, os conjuntos dos grupos Tl apresentaram os valores mais elevados.

Mesmo com o avanço dos sistemas de implantes, visando aumentar a estabilidade dos componentes, a ocorrência de infiltração microbiana pelas interfaces implantes-pilares das conexões testadas era esperada, considerando que o diâmetro médio das menores bactérias da cavidade bucal varia entre 0,3 - 0,7 um (Love e Jenkinson 2002; Weart et al., 2007) e que os valores dos gaps entre implantes e seus componentes pode variar de 2,3 até 100 mm (Tsuge et al., 2008; do Nascimento et al., 2015), dependendo da geometria da conexão e da presença de tensões mecânicas.

A diversidade de bactérias bucais exibe uma grande variedade morfológica, e as mais conhecidas apresentam entre 0,4 e 2 um de diâmetro e entre 0,5 e $5 \mu \mathrm{m}$ de comprimento (Young, 2006). A maioria das espéciesalvo testadas no presente estudo eram relativamente pequenas, com um comprimento ou diâmetro inferior a $2 \mu \mathrm{m}$.

Corroborando com os achados apresentados em um estudo de Coppedê et al. (2013), onde os mesmos modelos de parafusos convencionais e experimentais foram comparados e diferiram seus resultados mecânicos quanto ao destorque em conexões HE e Tl, também 
pudemos observar que os distintos parafusos de retenção influenciaram nos resultados microbiológicos. Eles concluíram que os parafusos experimentais cônicos evidenciaram valores de destorque mais elevados do que os parafusos planos convencionais, antes e após a simulação de carregamentos externos. Nossos resultados revelaram que os conjuntos fixados com parafusos experimentais apresentaram contagens mais baixas de micro-organismos do que aqueles fixados com parafusos convencionais.

Também corroborando com estes resultados, Arnetz et al. (2015) demonstraram que a geometria do parafuso de retenção influencia significativamente na perda de torque em conexões internas. Segundo os autores, os parafusos cônicos mostraram valores de destorque mais elevados do que os parafusos convencionais.

Os implantes HE fixados com parafusos experimentais cônicos apresentaram resultados negativos para todos os 38 micro-organismos testados. Nenhum sinal de hibridização microbiana pôde ser detectado pelo método DNA Checkerboard. Uma possível explicação é que os gaps nestes conjuntos foram significativamente reduzidos após a fixação dos componentes e tiveram uma penetração microbiana limitada.

Embora nenhuma das conexões protéticas em implantodontia possa impedir totalmente a infiltração de micro-organismos e fluidos em suas interfaces, a maior estabilidade dos conjuntos visa retardar ou reduzir a penetração e a colonização microbiana. Além disso, as condições de crescimento microbiano podem ser restringidas em um ambiente com nutrientes reduzidos, também pelas reduções dos gaps entre os 
componentes protéticos, o que pode resultar em morte das células microbianas e degradação dos seus DNAs ao longo do tempo (LoyolaRodriguez et al., 1992).

Outra justificativa pode estar relacionada com a condição estática de incubação dos conjuntos. Os gaps na interface implante-pilar podem não ter sido suficientes para produzir a infiltração e consequentemente o crescimento bacteriano. Sob condições dinâmicas de carregamentos, o efeito produzido pelos micromovimentos dos componentes durante a ciclagem mecânica pode facilitar a infiltração de micro-organismos/fluidos para o interior dos implantes.

Adicionalmente, alguns estudos utilizando métodos baseados em cultura ou sondas de DNA comprovaram a infiltração por meio da interface implante-pilar, mesmo em condições estáticas (Teixeira et al., 201 1; Cardoso et al., 2015).

No entanto, considerando as pequenas dimensões das bactérias que colonizam a cavidade bucal e que as conexões dos sistemas de implantes ainda são falíveis na prevenção de infiltração de microorganismos/fluidos, uma explicação mais plausível para a ausência de sinais de hibridização pela técnica DNA Checkerboard pode ser creditada à sensibilidade de detecção desta metodologia. O limite mínimo de hibridização por este método é de 104 células (genomas), o que significa que a contagem de genoma no intervalo de 1-1000 poderia ter estado presente nas partes internas dos implantes, mas não pôde ser detectado pelo mesmo. 
Mesmo com esta limitação, os resultados podem ser clinicamente relevantes, uma vez que os dados fornecidos sugerem que, se não houve detecção devido à sensibilidade limitada do método, as espécies que eventualmente colonizariam as superfícies internas dos implantes seriam em quantidades relativamente muito pequenas, o que não poderia refletir em manifestações clínicas inflamatórias/infecciosas.

Ademais, espécies associadas à peri-implantite, tais como Porphyromonas gingivalis, Tannerella forsythia e Treponema denticola, não foram detectadas ou então encontradas em pequenas contagens nos conjuntos fixados com os parafusos experimentais cônicos.

As características específicas destas espécies patogênicas estão relacionadas à colonização dos sulcos gengivais, com a consequente migração para os tecidos peri-implantares. Os produtos do seu processo de metabolismo, tais como proteases e exotoxinas, estão intrinsecamente associados a respostas imunes destrutivas, agindo na promoção do processo inflamatório e a perda óssea (Tonetti e Schmid, 1994). Portanto, mais estudos microbiológicos que envolvam a associação de microscopia eletrônica de varredura e simulação de cargas podem colaborar para elucidar essas hipóteses.

\section{Contribuição Clínica do Estudo}

Apesar de pouca diferença estatística entre os parafusos convencionais e os modificados quanto à passagem de micro-organismos em termos de espécies detectadas, a quantidade absoluta de micro- 
organismos que infiltraram para as conexões do tipo Hexágono Externo com parafusos experimentais cônicos foi significantemente menor que aquelas dos outros 3 grupos (HE com parafuso convencional e Tl com parafuso convencional ou experimental). Assim, sugere-se que sejam realizados estudos clínicos comparando-se os sistemas Hexágono Externo com parafusos convencionais e com modificados para se comprovar a superioridade do conjunto. Caso confirmada por estudo in vivo, esses parafusos modificados podem abrir novas possibilidades de tratamento com possível aumento na longevidade dos implantes. 
7. Conclusões 



\section{Conclusões}

Dentro das limitações desta etapa in vitro do estudo, podemos concluir que:

1. Um significativo número de espécies microbianas encontradas em saliva humana penetrou por meio da interface implantepilar nas conexões em hexágono externo (HE) e triângulo interno (TI) avaliado;

2. As conexões fixadas com parafusos experimentais cônicos apresentaram menores contagens de micro-organismos quando comparadas às fixadas com parafusos convencionais;

3. O conjunto HE fixado com parafusos experimentais cônicos foi o que apresentou a melhor combinação para prevenção da microinfiltração bacteriana. 

Bibliografia 



\section{BIBLIOGRAFIA ${ }^{1}$}

Alves D.C., Carvalho P.S.P., Elias C.N., Vedovatto E., Martinez E.F. In vitro analysis of the microbiological sealing of tapered implants after mechanical cycling. 2016. Clin Oral Invest DOI 10.1007/s00784-016-1744-0.

Baggi L., Di Girolamo M., Mirisola C., Calcaterra R. 2013. Microbiological evaluation of bacterial and mycotic seal in implant systems with different implant-abutment interfaces and closing torque values. Implant Dent 22:344350.

Brånemark PI., Adell R., Breine U., Hansson B.O., Lindström J., Ohlsson A. Intraosseous anchorage of dental prostheses. I. Experimental studies. Scand J Plast Reconstr Surg 1969; 3(2): 81-100.

Brånemark P.I., Hansson B.O., Adell R., Breine U., Lindström J., Hallén O., Ohman A. Osseointegrated implants in the treatment of the edentulous jaw. Experience from a 10-year period. Scand J Plast Reconstr Surg 1977; 16/Suppl $1): 1-132$.

Brånemark P.I., ZARB G.A., ALBREKTSSON T. ed. Tissue-Integrated Prosthesis: Osseointegration in Clinical Dentistry. Chicago: Quintessence, 1985.

Coppedê A.R. Estudo mecânico da conexão implante/abutment utilizando parafusos convencionais e parafusos experimentais cone morse. Ribeirão Preto, 2011. 196p. Tese (Doutorado em Reabilitação Oral). Faculdade de Odontologia de Ribeirão Preto, Universidade de São Paulo.

D. Martin-Gili, M. Molmeneu, M. Fernandez, M. Punset, Ll. Giner, J. Armengou, F. Javier Gil, J Mater Sci. Determination of fluid leakages in the different screw-retained implant-abutment connections in a mechanical artificial mouth. Mater Med (2015) 26:21 1. DOI 10.1007/s10856-015-5544-x.

do Nascimento C., Miani P.K., Pedrazzi V. et al. Leakage of saliva through the implant-abutment interface: in vitro evaluation of three different implant connections under unloaded and loaded conditions. Int J Oral Maxillofac Implants. 2012 May-Jun;27(3):551-60.

do Nascimento C., Barbosa R.E.S., Issa J.P.M., Watanabe E., Ito I.Y., Monesi N., Albuquerque Junior R.F. The use of fluorescein for labeling genomic probes in the checkerboard DNA-DNA hybridization method. Microbiological Research 2008; 163(4): 403-407.

\footnotetext{
1 UNIVERSIDADE DE SÃO PAULO. Sistema Integrado de Bibliotecas. Diretrizes para apresentação de Dissertações e Teses da USP: documento eletrônico e impresso. São Paulo: SIBi/USP, 2009. 100p
} 
Guda T., Ross T.A., Lang L.A., Millwater H.R. Probabilistic analysis of preload in the abutment screw of a dental implant complex. J Prosthet Dent 2008; 100(3): 183-193.

Guindy J.S., Besimo C.E., Besimo R., Schiel H., Meyer J. Bacterial leakage into and from prefabricated screw-retained implant-borne crowns in vitro. J Oral Rehabil 1998; 25(6):403-408.

Harder S., Quabius E.S., Ossenkop L., Kern M. (2012). Assessment of lipopolysaccharide microleakage at conical implant-abutment connections. Clin Oral Invest 16:1377-1384.

Hobo, S.; Ichida, E.; Garcia, L.T. Osseointegração e reabilitação oral. São Paulo: Santos, 1997.336p.

Jansen V.K, Conrads G., Richter E.J. Microbial leakage and marginal fit of the implant-abutment interface. Int J Oral Maxillofac Implants 1997; 12(4):527-540.

Kitagawa T., Tanimoto Y., Odaki M., Nemoto K., Masahiro A. Influence of implant/abutment joint designs on abutment screw loosening in a dental implant system. J Biomed Mater Res B Appl Biomater 2005; 75(2): 457-463.

Khraisat A., Baqain Z.H., Smadi L., Nomura S., Miyakawa O., Elnasser Z. Abutment rotational displacement of external hexagon implant system under lateral cyclic loading. Clin. Implant Dent. Relat. Res 2006; 8(2): 96-99.

Magini, R.S.; Schiochett C. Históricos dos implantes: do sonho à realidade. Rev. Bras. Odontol., v. 56, n. 5, p. 245-251, 1999.

Martin W.C., Woody R.D., Miller B.H., Miller A.W. Implant abutment screw rotations and preloads for four different screw materials and surfaces. J Prosthet Dent 2001; 86(1): 24-32.

Meffert, R.M.; Langer, B.; FRITZ, M.E. Dental implants: a review. J Periodontol, Chicago, v.63, n.11, p.859-870, 1992.

Merz B.R., Hunenbart S., Belser U.C. Mechanics of the implant-abutment connection: an 8-degree taper compared to a butt joint connection. Int J Oral Maxillofac Implants 2000; 15(4): 519-526.

Mombelli A., Decaillet F. (2011). The characteristics of biofilms in peri-implant disease. J Clin Periodontol 38(Suppl. 11):203-213.

Piattelli A., Scarano A., Paolantonio M., Assenza B., Leghissa G.C., Di Bonaventura G., Catamo G., Piccolomini R.. Fluids and microbial penetration in the internal part of cement-retained versus screw-retained implantabutment connections. J Periodontol 2001; 72(9):1146-1150. 
Pita M.S., Anchieta R.B., Ribeiro A.B., Pita D.S., Zuim P.R.J., Pellizzer E.P. Fundamentos de oclusão em implantodontia: orientações clínicas e seus determinantes protéticos e biomecânicos. Rev Odontol Araçatuba 2008; 29(1): 53-59.

Pita M.S. Estudo biomecânico de conexões implante/pilar com parafusos convencionais e parafusos modificados tipo Cone Morse: análise tridimensional pelo método dos elementos finitos. Ribeirão Preto, 2013. 121 p. Tese (Doutorado em Reabilitação Oral). Faculdade de Odontologia de Ribeirão Preto, Universidade de São Paulo.

Pita M.S., do nascimento C., dos Santos C.G, Pires I.M., Pedrazzi V. Experimental conical-head abutment screws on the microbial leakage through the implant abutment interface: Na in vitro analysis using targetespecifics DNA probes. Clin Oral Implants Res. 2016 May 19. doi: $10.1111 / c \mid r .12876$.

Quek H.C., Tan K.B., Nicholls J.I. Load fatigue performance of four implantabutment interface designs: effect of torque level and implant system. Int J Oral Maxillofac Implants 2008; 23(2): 253-262.

Quirynen M., Bollen C.M., Eyssen H., Van Steenberghe D. Microbial enetration along the implant components of the Branemark System. Clin Oral Implants Res 1994; 5(4): 239-244.

Resende, L.C.N. Interação biológica implante tecido-ósseo. São Paulo: Almed, 1994. 173p.

Romanos G.E, Biltucci M.T., Kokaras A., Paster B.J. (2014). Bacterial composition at the implant-abutment connection under loading in vivo. Clin Implant Dent Relat Res. doi:10.1111/cid. 1227.

Sakaguchi R.L., Borgersen S.E. Nonlinear contact analysis of preload in dental implant screws. Int J Oral Maxillofac Implants 1995; 10(3): 295-302.

Schwarz MS. Mechanical complications of dental implants. Clin Oral Implants Res (2000); 11 (Suppl 1): 156-158.

Silva-Neto J.P, Nóbilo M.A.A, Penatti M.P.A, PC S. Jr., Neves F.D. Influence of methodologic aspects on the results of implant-abutment interface microleakage tests: a critical review of in vitro studies. Int J Oral Maxillofac Implants 2012. 27:793-800.

Skalack, R. Biomechanical considerations in osseointegrated prostheses. J. Prosthet. Dent., Saint Louis, v. 49, n. 6, p. 843-848, Jun., 1983.

Socransky S.S., Cibbons R.J., Dale A.C., Bortnick L., Rosenthal E., MacDonald J.B. The microbiota of the gingival crevice in man-I. Total microscopic and 
viable counts and counts of specific organisms. Arch Oral Biol 1963; 8: 275280.

Socransky S.S.Smith C., Martin L., Paster B.J., Dewhirst F.E., Levin A.E. "Checkerboard" DNA-DNA hybridization. Biotechniques 1994; 17(4): 788-792.

Socransky S.S., Haffajee A.D., Amith C., Martin L., Haffajee J.A., Uzel N.G., Goodson J.M. Use of checkerboard DNA-DNA hybridization to study complex microbial ecosystems. Oral Microbiol Immunol 2004; 19(6): 352-362.

Steinebrunner L., Wolfart S., Bossmann K., Kern M. In vitro evaluation of bacterial leakage along the implant-abutment interface of different implant systems. Int J Oral Maxillofac Implants 2005; 20(6): 875-881.

Taylor T.D., Agar J.R., Vogiatzi T. Implant prosthodontics: current perspective and future directions. Int J Oral Maxillofac Implants 2000; 15(1): 66-75.

Teixeira W., Ribeiro R.F., Sato S., Pedrazzi V. Microleakage into and from twostage implants: an in vitro comparative study. Int J Oral Maxillofac Implants $2011 ; 26(1)$ : 56-62. 
Anexo 

ANEXo 1. Parecer Consubstanciado do CEP.

\section{FACULDADE DE ODONTOLOGIA DE RIBEIRÃO PRETO/ FORP/ USP}

\section{PARECER CONSUBSTANCIADO DO CEP}

\section{DADOS DO PROJETO DE PESQUISA}

Título da Pesquisa: Estudo de conexb̄es protéticas em implantodontia com parafusos convencionais e experimentais cônicos: análise biomecánica pelo método dos elementos finitos $3 \mathrm{~d}$ e microbiológica pela técnica DNA Checkerboard e 165 rDNA-based PCR

Pesquisador: Vinícius Pedrazzi

Área Temática:

Versäo: 3

CAAE: 29826714.6 .0000 .5419

Instituição Proponente: Universidade de Sao Paulo

Patrocinador Principal: Financiamento Prỏprio

\section{DADOS DA NOTIFICAÇÃO}

Tipo de Notificaçäo: Envio de Relatónio Parcial

Detalhe:

Justificativa:

Data do Envio: 19/02/2015

Situação da Notifieaçäo: Parecer Consubstanciado Emildo

\section{DADOS DO PARECER}

Número do Parecer: 969.000

Data da Relatoria: 25/02/2015

Apresentagão da Notificaçäo:

Adequada.

Objetivo da Notificaça:

Apresentação de Relatório Parcial, com solicitação de prorrogação de prażo por 04 meses. Justifica-se a prorrogação pela dificuldade em obtenção do material necessário para a pesquisa.

Avaliağão dos Riscos e Beneficios:

Em conformidade com o descrito no Projeto.

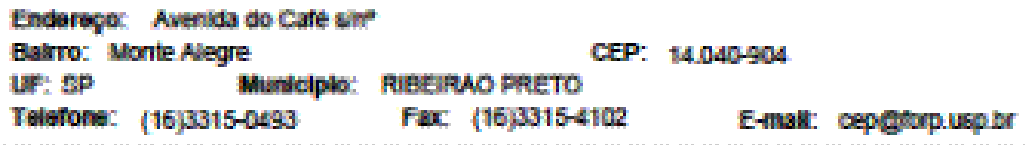

